\title{
ON THE INTERACTION OF ASPECT AND MODAL AUXiliaries ${ }^{1}$ \\ Valentine Hacquard \\ UMass, Amherst
}

\begin{abstract}
This paper discusses the interaction of aspect and modality, and focuses on the puzzling implicative effect that arises when perfective aspect appears on a 'root' modal: perfective somehow seems to force the proposition expressed by the complement to hold in the actual world, and not merely in some possible world. While all root interpretations of modal auxiliaries (in a language like French) yield the effect, epistemic and addressee-oriented deontic interpretations do not. I show that implicative readings are contingent on the relative position of the modal w.r.t. aspect, and propose a way to derive these readings with perfective, but not with imperfective aspect, while maintaining a fairly conservative semantics for both aspect and modals.
\end{abstract}

\section{INTRODUCTION}

Tense and modality are undeniably interconnected: what was a possibility a month ago may not be one today. Tense and aspect are likewise related: a punctual event that took place yesterday may not hold at present, but a more durative event (or state) may still. This paper focuses on the perhaps less-studied interaction of aspect and modality.

Aspect's role is to relate the running time of an event to a time of reference: perfective aspect places the running time of an event within a reference time interval (provided by tense or by time adverbials), while imperfective places the running time of an event around that reference interval. This is captured formally by treating aspects as quantifiers over events, which take a predicate of events (a verb) and return a predicate of times, which, in turn, combines with a time to return a proposition (cf. Kratzer 1998, a.o.). The French example below illustrates:
a. Hier matin, Jane lisait un livre.
Yesterday morning, Jane read-past-imp a book.
$\exists \mathrm{t} \exists \mathrm{e}[\mathrm{t} \subseteq \tau(\mathrm{e}) \& \mathrm{~J} . \operatorname{read}$ a $\operatorname{book}(\mathrm{e})]$
b. Hier matin, Jane a lu un livre.
Yesterday morning, Jane read-past-pfv a book.
$\exists \mathrm{t} \exists \mathrm{e}[\tau(\mathrm{e}) \subseteq \mathrm{t} \& \mathrm{~J}$. read a book(e)]

In (a) the event of Jane reading a book surrounds the reference time (yesterday morning), while in (b) the reading_a_book event is contained within yesterday morning (and hence, it is implied with (b) but not (a) that Jane finished her book).

\footnotetext{
${ }^{1}$ I am greatly indebted to Gennaro Chierchia, Kai von Fintel, Irene Heim and Sabine Iatridou for all of their help with this project. For helpful discussions, I would also like to thank Marta Abrusan, Pranav Anand, Angelika Kratzer and participants of the ling720 seminar at UMass Amherst, and the audience at Sinn und Bedeutung 11.
} 
Modal words are used to talk about possibilities and necessities. We can talk about the ways the world should be, were there peace on Earth, how it might have been, would Christopher Columbus not have landed in America, etc... This ability to go beyond directly observable facts is indeed at the heart of the meaning of modal expressions, and is neatly captured formally by invoking the notion of 'possible worlds' (cf. Kripke 1963, Lewis 1973, Kratzer 1981, 1991, a.o.). There is a multitude of ways the world could be, and each possible world represents a different variant, a different state of affairs. What modal auxiliaries do is 'quantify' over different sets of worlds. Thus, a sentence like 'Jane must go to bed at 9:00pm' states that in all accessible worlds among a certain set (e.g., in all possible worlds in which Jane’s parents' orders are obeyed), Jane goes to bed at 9. The necessity part of the meaning comes from the fact that the sentence is universally quantified: Jane goes to bed at 9 not just in some but in all worlds in which she obeys her parents. A possibility obtains by quantifying over some accessible world: 'Jane may watch $T V$ ' means that there is (at least) a world in which Jane watches TV and still obeys her parents. Note that in both cases the actual world is not necessarily one of the accessible worlds: sadly for her parents, Jane may be a very disobedient girl in reality, and hence never go to bed at 9 . However, we still judge the sentence to be true.

Modals, then, enable us to talk about non actual (but possible) situations by invoking worlds other than the actual one. The actual world may, of course, be one of the accessible worlds: this happens when the accessibility relation (i.e., the selection function which determines which worlds are being quantified over) is reflexive. An accessibility relation relates a world of evaluation (the actual world in an unembedded-or matrix-context) to a set of (accessible) worlds in which certain propositions hold. With a reflexive accessibility relation, the world of evaluation is one of the accessible worlds. This happens, for instance, with an epistemic accessibility relation, which picks a set of worlds compatible with what is knwon in the world of evaluation. Because an epistemic relation is reflexive, in an epistemic statement such as 'in view of what is known, Jane may be the murderer', the actual world is one of the accessible worlds (i.e., it is compatible with what is known). Crucially, however, the actual world itself doesn't have to be a world in which the complement holds: the sentence is true if the complement is true in some accessible world, but because it doesn't have to be true in all accessible worlds (may is an existential quantifier), it doesn't have to be true in the actual world: the sentence is true if Jane turns out not to be the murderer in reality. Put another way, 'Jane may be the murderer and Paul 
may be the murderer' is not a contradiction: there is a world compatible with what is known in which Jane is the murderer and a world compatible with what is known as well in which Paul is the murderer (the actual world could be either one these worlds or neither one of them).

While our current semantics for aspects and modals are rather successful on their own, they cannot, when combined, capture the puzzle I am about to describe.

As first discovered for the ability modal by Bhatt (1999), in certain languages (like French), certain modal constructions require their complement to hold in the actual world, and not merely in some possible world. However this requirement obtains only when the modals are marked with perfective aspect. Consider the following example 2 :
a. Pour aller au zoo, Jane pouvait
prendre le train.
To go to the zoo, Jane can-past-impf take the train
b. Pour aller au zoo, Jane a pu prendre le train.
To go to the zoo, Jane can-past-pfv take the train
'To go to the zoo, Jane could (was able to) take the train.'

The truth conditions of (2)a) are as follows: there is a world among all accessible worlds in which Jane goes to the zoo where she took the train to get there. This is compatible with a scenario in which Jane did not take the train in reality (nor went to the zoo, for that matter). Things are different with (2)b): for the sentence to be true, Jane must have taken the train in the actual world. Any continuation stating that she, in fact, did not, comes out as a contradiction. I will follow Bhatt in calling this effect of having the complement forced to hold in the actual world, an 'actuality entailment'. As we will see, we are dealing with an entailment rather than an implicature: the implication that the complement holds in the actual world cannot be cancelled.

Note that the effect can only be seen in languages that have an overt aspectual distinction such as French, Italian, Catalan, Bulgarian, Greek, Hindi. ${ }^{3}$ Because English doesn’t distinguish between the two aspects overtly, the actuality entailment goes undetected. To get a feel for the data in English, the following examples involving the predicate able help bring about, via temporal adverbials, the perfective meaning (and hence, an implicative interpretation) in (a) and the imperfective one (and hence, a non implicative interpretation) in (b):

\footnotetext{
${ }^{2}$ The modality involved here is 'goal-oriented' or 'teological' modality (cf. von Fintel and Iatridou 2005), and not a pure ability modal, which was the modal interpretation Bhatt (1999) discusses. We will turn shortly to the difference in meaning between the various flavors of modality.

${ }^{3}$ Albanian, Basque, Galicean, Portuguese and Spanish seem to have an extra counterfactual reading with perfective (cf. Bhatt 1999, Brogonovo and Cummins 2006). I put this complication aside and focus on French and Italian.
} 
b. Back in the days, firemen were able to eat 50 apples.

Turning back to our French examples, the overt difference between (2)a) and (2)b) is the aspectual morphology on the modal: the former shows imperfective (imparfait) and the latter perfective (passé composé) aspect. At the descriptive level, it appears as if perfective somehow neutralizes the modality and forces the complement to hold in the actual world. But this is puzzling in at least two respects. First, why should there be a difference in 'actuality entailment' between perfective and imperfective? Both are using the same modal in the same sense (we are presumably dealing here with a circumstantial modal, having to do with certain relevant facts or circumstances of the base world, restricted by a purpose clause). Whatever the meaning of one, we would expect the other to vary along an aspectual/durational dimension, and not a modal one. The second issue is that the modal involved looks like the archetypal possibility modal (at least based on its other usages when we give it a deontic or an epistemic interpretation). All that (2)b) should say is that there was some accessible world (i.e., some possibility) in which she took the train: how can we force this world to be the actual one?

Importantly, the effect is also found with the universal counterpart of (2):
a. Pour aller au zoo, Jane devait prendre le train. To go to the zoo, Jane must-past-impf take the train
b. Pour aller au zoo, Jane a dû prendre le train. To go to the zoo, Jane must-past-pfv take the train 'To go to the zoo, Jane had to take the train'.

Here again, perfective morphology in (4)b) forces the complement to hold in the actual world, while the corresponding sentence with imperfective in (4)a) imposes no such restriction. (2)b) and (4)b) are both true in situations where Jane actually took the train and went to the zoo and false in situations where she didn't take the train. However, the two are not interchangeable: one is an (actualized) possibility, the other, an (actualized) necessity. With the latter, taking the train was the only possible option. With the former, other options might have been available, and we get the further impression that taking the train was Jane’s preferred way to get to the zoo.

The main question that this paper addresses is how to derive these actuality entailments. What is responsible for the apparent eradication of the very property of 'displacement' that defines modals? What are the semantics of aspect and modals such that actuality entailments 
arise in certain environments and not others? Which modal interpretations are sensitive to aspect and yield actuality entailments, and which do not? For those that do not, what makes them immune to this effect?

For one, it appears that the actuality entailment cannot be reduced to a pragmatic effect: no matter what context we build, the inference is not defeasible, unlike the actuality implication that arises with closely related (meaning-wise) have the possibility:

(5) Jane a eu la possibilité de prendre le train, mais elle ne l’a pas pris. Jane had-pfv the possibility to take the train, but she didn’t take it.

Second, I would like to eliminate immediately what I feel is a non-starter. There is one technical trick that could derive actuality entailments in (2) and (4). This trick would involve restricting the domain of quantification to only one world: if the accessibility relation is reflexive and furthermore only picks one world, and in that world the complement holds, then necessarily, the complement will hold in the actual world. A good candidate for such an accessibility relation is Kratzer's 'totally realistic' conversational background ${ }^{4}$ (in view of what is the case...), which does exactly this by depicting the actual world in such detailed way that it uniquely describes it. Putting aside skepticism about the existence of such an accessibility relation (e.g., what is the difference between this kind of modality and no modality at all?), we still cannot get it to work. We can use (2)a) and (2)b) against the same conversational background: we are talking about Jane wanting to go to the zoo and the options available to her at that time, etc... Why would the version with perfective aspect force a totally realistic conversational background, and the one with imperfective not? We could stipulate that this is precisely what perfective does: it indicates or forces a totally realistic conversational background. But as we will see shortly, perfective on a modal doesn't always yield an actuality entailment. Moreover, consider the difference between the actuality entailments derived with the possibility modal pouvoir and the necessity one devoir. While a totally realistic conversational background may not be required for the actuality entailment to go through, given that we have universal quantification (as long as the modal base is reflexive and there is no ordering source ${ }^{5}$ ), we would still lack an explanation for the

\footnotetext{
${ }^{4}$ In Kratzer's system, a conversational background is, roughly speaking, an accessibility relation.

${ }^{5}$ In Kratzer's system, a modal is restricted by two conversational backgrounds. A first conversational background gives you the worlds of the modal base (the accessible worlds). The ordering source is a second conversational background whose role is to order the worlds of the modal base according to some contextual ranking.
} 
difference between the two aspects. Invoking our trick that perfective correlates with a totally realistic conversational background could not derive a meaning difference between (2)b) and (4)b): Because a totally realistic accessibility relation only picks out one world, the base world (the actual world in matrix contexts), there shouldn't be any difference in meaning between universal and existential quantification.

Assuming then that the 'actuality entailment' effect is semantic rather than pragmatic, and that it doesn't involve a 'totally realistic' modal base, there are (at least) three theoretical moves one can make: the first is to deny that we are dealing with a modal. This is the option Bhatt ends up arguing for: despite appearances, the ability modal (which yield actuality entailments with perfective) is not a modal; it is an implicative predicate, which asserts the truth of its complement. The modal reading that emerges with imperfective is not due to the semantics of the ability modal per se, but rather results from combining it with a modal element (a generic operator), itself associated with imperfective morphology. As we will see, the problem with such a move is that it treats the ability modal as a completely separate construction from other modals, despite the fact that cross-linguistically the same lexical item (e.g., pouvoir) is used to express abilities as to express, e.g., permission or epistemic possibility. The second option is to maintain that the modals that yield actuality entailments are modals, and that something in the semantics of perfective removes their modal dimension. The problem with this option is that certain interpretations of the same modal auxiliaries (epistemics and a subset of deontics), perfective doesn't yield actuality entailments; thus we don't want to make the semantics of the perfective too strong. Furthermore, we will see truth conditional evidence that the modality doesn't completely disappear, in cases of actuality entailments. The last option is to maintain that the modals that yield entailments are modals and remain modals even with perfective. The 'actuality entailment' would be an additional side effect of the combination of the two. This last option, if attainable, would be the most desirable, given that it would allow us to maintain a unified semantics both for modals and for perfective aspect. This is thus the option that I will pursue.

This paper is organized as follows. Section 1 goes over the different interpretations of modal auxiliaries and see which are sensitive to aspect w.r.t. actuality entailments, and which aren't. We will see that those that do are the 'root' interpretations, and those that do not are the epistemics and addressee-oriented deontics. I hypothesize that the reason why the latter are immune to the actuality entailment effect is the fact that they are interpreted above aspect. I show 
how to derive actuality entailments with perfective on root modals in section 2, and how to avoid them with imperfective in section 3. I briefly review previous proposals in section 4.

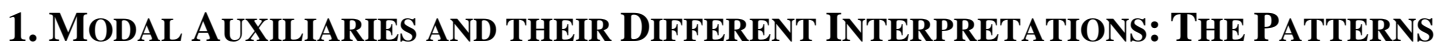

\subsection{A Unified AcCount of Modal Auxiliaries (Kratzer 1981, 1991)}

In a possible worlds framework, modals are taken to be quantifiers over possible worlds (cf. Kripke 1962, Lewis 1973, Kratzer 1981, 1991, a.o.). If I utter the sentence 'Jane may have a brother', I claim that there is a possibility that Jane has a brother. Or, in possible worlds talk, there is a possible world, among those compatible with what I know, in which Jane has a brother. A possibility modal (e.g., may) existentially quantifies over worlds, the way some existentially quantifies over individuals. Just like there are existential (some) and universal (every) quantifiers over individuals, there are existential (may, can, pouvoir...) and universal (must, devoir...) quantifiers over possible worlds. If I had said 'Jane must have a brother', I would have claimed that in all worlds compatible with what I know, Jane has a brother.

Notice that I snuck in a restriction. I did not say that there is a possible world among all possible worlds in which Jane has a brother. Rather, I restricted the domain of quantification to those worlds which are compatible with what I know. This is an epistemic accessibility relation (i.e., having to do with knowledge/evidence ${ }^{6}$ ). This restriction plays an analogous role to the NP which restricts the domain of quantification of some, as in 'some man smokes': there is an individual $\mathrm{x}$, among the set of men, such that x smokes. Similarly, there is a world, among those that are compatible with what is known, in which Jane has a brother.

We just saw an instance of an epistemic accessibility relation. Our modal may can also be used with a deontic sense (having to do with laws or regulations), as in 'Jane may not watch TV'. In that case, the accessibility relation would be deontic and thus restrict the domain to those worlds in which the rules established by Jane's parents are obeyed. In none of these worlds does Jane watch TV. The same modals can thus have many flavors, depending on the type of accessibility relation that restricts them. The way we're able to identify which flavor a speaker has in mind seems to depend on the context in which these modal statements are made. For instance, if we're talking about what Jane is allowed to do, we'll naturally interpret a modal as

\footnotetext{
${ }^{6}$ For the purposes of this paper, I remain purposefully vague on whether epistemics involve knowledge, evidence, or beliefs, and whose knowledge/evidence/beliefs the modal reports.
} 
being deontic. Kratzer (1981) proposes to derive the contextual nature of these accessibility relations via conversational backgrounds. In her system, each modal auxiliary has a single lexical entry, which provides its quantificational force (existential or universal). These quantifiers are restricted by a conversational background, a modal base, which is contextually determined, and which can be brought about by phrases such as in view of what the law says. Let's start with an example:

(6) In view of what the law says, Jane must not steal.

The sentence in (6) does not mean that Jane does not steal in reality; she may be a convicted felon and (6) would still be judged true. Instead, the modal allows us to talk about ideal situations: in our case, ideal w.r.t. the law: we want our modal to quantify over worlds in which the law is obeyed. The background here is what the law says. Thus, we could have a modal base $f_{\text {deontic }}(w)$, that is, a set of propositions, such that each of these propositions expresses the content of a law in the base world w: e.g., there are no thieves. In all of the worlds where the law is obeyed, Jane does not steal.

A complication arises and can be brought to light with cases in which the law is broken. Imagine that Jane actually steals. Then, according to the law:

(7) Jane must go to jail.

The problem is that our body of laws and regulations already exclude worlds in which there are thieves. Thus in all worlds in which the law is obeyed, Jane does not go to jail, because in all of these worlds, there is no crime. To get out of this conundrum, Kratzer proposes a second conversational background, the ordering source, which orders the worlds of the modal base according to an ideal, set by a body of laws. It is now the ordering source which gives the modal its deontic flavor. The modal base, on the other hand, is now 'circumstantial': it is made up of the set of relevant facts of the base world. It will notably contain the fact that Jane stole. The ordering source will be a set of propositions L, which describe a body of laws (e.g., there are no thieves, there is no murder, thieves go to jail, murderers go to jail...). This set of propositions $L$ will impose the following ordering: 
Ordering $\leq_{\mathrm{L}}$ :

For all worlds $\mathrm{w}, \mathrm{z} \in \mathrm{W}: \mathrm{w} \leq_{\mathrm{L}} \mathrm{z}$ iff $\{\mathrm{p}: \mathrm{p} \in \mathrm{L}$ and $\mathrm{z} \in \mathrm{L}\} \subseteq\{\mathrm{p}: \mathrm{p} \in \mathrm{L}$ and $\mathrm{w} \in \mathrm{L}\}$

The ordering states that a world w will be more ideal than a world $\mathrm{z}$, if more of the propositions in set $\mathrm{L}$ hold in $\mathrm{w}$ than in $\mathrm{z}$. Thus, the best worlds according to this ordering source will be those in which no law is broken. A slightly less ideal world will have one law broken (e.g., Jane stole), but the others obeyed (Jane goes to jail), etc. Given that the circumstantial modal base picks a set of worlds in which Jane stole, the best worlds in this set will be those in which there is a thief, Jane, but where she goes to jail (i.e., one of the propositions in L doesn't hold, but the others do).

To sum up, a necessity modal is a universal quantifier over possible worlds. With a deontic interpretation, it is first restricted by a circumstantial modal base $f(w)$, which returns a set of worlds in which certain facts in w hold (e.g., Jane stole a car). The set of worlds given by $\mathrm{f}(\mathrm{w})$ are then ordered by an ordering source $\mathrm{g}(\mathrm{w})$, according to an ideal provided by the law. Note that both $\mathrm{f}(\mathrm{w})$ and $\mathrm{g}(\mathrm{w})$ are contextually determined. This allows for a single entry for must:

(9) For any world $w$, conversational backgrounds $f, g$, and proposition $q$ :

$[[$ must $]](w)(f)(g)(q)=1$ iff $\forall \mathrm{w}^{\prime} \in \max _{\mathrm{g}(\mathrm{w})}(\cap f(w)): \mathrm{q}\left(w^{\prime}\right)=1$.

Where $\max _{g(w)}$ is the selection function that selects the set of $\leq_{g(w)}$-best worlds.

For Kratzer, there are two kinds of modal bases. First is the epistemic one, which picks the set of worlds compatible with what is known in w. The second is the circumstantial modal base. To get at the contrast between the two modal bases, consider the pair of examples below. English might and can help bring out this contrast, as they each have some selectional constraints which forces might and disallows can to select an epistemic modal base. With French and Italian pouvoir/potere, either modal bases are available:

a. Hydrangeas might be growing here.

b. Hydrangeas can grow here.

[Kratzer (1981)]

The sentence in (a) is evaluated against an epistemic modal base: to the best of my knowledge, it is possible that hydrangeas are growing here. The sentence in (b) is evaluated against a circumstantial modal base, that is, one which picks out worlds in which certain facts of the world hold. Such facts will include the quality of the soil, the climate, etc. While the difference in meaning might seem subtle, they actually yield different truth conditions. If I know for a fact that 
there are no hydrangeas in this part of the country, (a) will be false; however, the circumstances for hydrangeas to grow might still be ideal, and the sentence in (b) will then be true.

To sum up, Kratzer shows that the different meanings that arise with modals can vary along three dimensions: the force (existential or universal), which is lexically determined; the modal base, which is either circumstantial (the modal base involved in all root modals) or epistemic. Finally, there is the ordering source, which follows the template in (8), and where what changes from one ordering source to the next is the set of propositions that establishes the ordering: deontic (laws), bouletic (wishes), teleological (aims), stereotypical (normal course of events). Both the modal base and the ordering source are contextually given, and not all combinations of modal bases and ordering sources are possible.

The modal flavors we will be primarily concerned with will be epistemics, deontics and a series of circumstantials. These circumstantials include abilities, as in 'Jane can lift this table'; pure circumstantials, as in 'hydrangeas can grow here'; and goal-oriented ones, as in 'Jane can take the train to go to Paris', which involves a circumstantial modal base (where the circumstances include things such as the train schedule, the fact that there are rail tracks from here to Paris, etc.), further restricted by the purpose clause: in some world compatible with certain facts of the actual world and where Jane goes to Paris, Jane takes the train in it.

\subsection{INTERPRETATIONS OF MODAL AUXILIARIES AND SENSITIVITY to ASPECT}

In this section we go over the different possible interpretations of modal auxiliaries and see which yield actuality entailments, and which do not. In brief, those that do are the 'root' modals, i.e., those with a circumstantial modal base: ability, goal-oriented and subject-oriented deontics. Those that don't are the epistemics and addressee-oriented deontics. The first interpretation to have been identified in the literature as yielding implicative readings with perfective is the ability modal (Bhatt 1999):

a. Jane a pu soulever cette table, \#mais elle ne l'a pas soulevée. Jane could-pfv lift this table, \#but she didn't lift it

b. Jane pouvait soulever cette table, mais elle ne l'a pas soulevée. Jane could-impf lift this table, but she didn't lift it 
As we saw in the introduction, another interpretation to yield this effect is the goaloriented one, which has to do with the possibilities and necessities circumstantially available to the subject, given certain goals of the subject. The following examples illustrate:

(12) a. Jane a pu prendre le train pour aller à Londres, \#mais elle a pris l'avion. Jane could-pfv take the train to go to London, \#but she took the plane

b. Jane pouvait prendre le train pour aller à Londres, mais elle a pris l'avion. Jane could-impf take the train to go to London, but she took the plane

(13) a. Jane a dû prendre le train pour aller à Londres, \#mais elle a pris l'avion. Jane must-pfv take the train to go to London, \#but she took the plane

b. Jane devait prendre le train pour aller à Londres, mais elle a pris l'avion. Jane must-impf take the train to go to London, but she took the plane

The above examples relate the possibility/necessity of taking the train, given Jane's goal to go to London. With perfective, both the possibility (12)a) and the necessity (13)a) modals require that Jane took the train in the actual world, whereas with imperfective, neither of them do.

Epistemics, on the other hand, do not yield actuality entailments with perfective. In the examples below, aspect does not affect the non-implicative behavior of modals, with an epistemic interpretation:

(14) a. (Selon la voyante,) Bingley a pu aimer Jane. (According to the fortune teller) Bingley could-pfv love Jane

b. (Selon la voyante,) Bingley pouvait aimer Jane. (According to the fortune teller) Bingley could-impf love Jane

(15) a. (Selon la voyante,) Bingley a dû aimer Jane. (According to the fortune teller) Bingley must-pfv love Jane

b. (Selon la voyante,) Bingley devait aimer Jane. (According to the fortune teller) Bingley must-impf love Jane

However, there still seems to be a meaning difference that arises from the aspect morphology on the modal. Let's look at (15) more closely. In (a) according to the fortune teller, it must be the case (at the time of utterance) that at some past time Bingley loved Jane (with an implication that he doesn't love her anymore). In (b) according to the fortune teller, it must be the case (at utterance time) that at some past time Bingley was in love with Jane (with no implication about whether he still does or not). The fortune teller could have expressed herself as follows: 
(16) a. Je pense que (l'été dernier) Bingley a aimé Jane. I think that (last summer) Bingley loved-pfv Jane

b. Je pense que (l'été dernier) Bingley aimait Jane. I think that (last summer) Bingley loved-impf Jane

We see that the epistemic necessity holds now, given the fortune teller's evidence at the time of utterance, about some past time. That past reference time (last summer) is included within the loving state with imperfective (b), while in (a) the reference time (last summer) contains the loving state (thus yielding an implication that the state doesn't hold anymore). One can transparently see in (16) that the temporal and aspectual morphology is interpreted in the complement. Thus in (14) as well, and despite the fact that the tense/aspect morphology (in French) appears on the modal itself, it is interpreted below it, namely on the complement clause. This is further brought out in the following examples. The adverb déjà (already) with perfective means something like 'once before'. With imperfective, it means 'already at the time'.

(17) a. Bingley a déjà aimé Jane.

Bingley has already loved Jane

'Bingley has loved Jane once before.'

b. Bingley aimait déjà Jane.

Bingley loved-impf already Jane

'Bingley was already in love with Jane.'

This is the interpretation we get when we add an epistemic modal:

a. Bingley a déjà dû aimer Jane.

Bingley has already must loved Jane

'Bingley must already have loved Mary (once before)'.

b. Bingley devait déjà aimer Jane.

Bingley loved-impf already Jane

'Bingley must already have been in love with Mary (at the time).'

What about deontics? Do they pattern with epistemic or with ability/teleological interpretations? At first blush, they also seem to yield actuality entailments:

(19) a. Lydia a pu aller chez sa tante (selon les ordres de son père).

Lydia could-pfv go to her aunt

$\rightarrow$ Lydia went to her aunt

b. Lydia a dû faire la vaisselle (selon les ordres de son père).

Lydia must-pfv do the dishes

$\rightarrow$ Lydia did the dishes 
There is, however, an important distinction to keep in mind, when discussing deontics, namely Feldman's (1986) ought-to-be vs. ought-to-do deontics. Observe the following contrast:

a. Murderers ought to go to jail.

b. Wickham ought to apologize.

The most natural interpretation of (20)a) is that it ought to be the case that murderers go to jail, rather than 'murderers have an obligation to go to jail'. While (20)b) can also have that meaning, the more straightforward reading is one where the obligation is on the subject himself: what Wickham ought to do is apologize. ${ }^{7}$ As the following example illustrates, the same sentence can have either one of these interpretations (cf. Bhatt 1998):

Kitty has to brush her teeth.

With the ought-to-do interpretation, the sentence in (21) expresses an action that the subject, Kitty, ought to do, if she doesn't want to get cavities, or be scolded by her mother. The sentence also has an ought-to-be interpretation, as in the case where it is uttered by Kitty's mother to the babysitter: the mother is placing an obligation on the babysitter directly, and not on Kitty: it ought to be that Kitty brushes her teeth.

I believe that there is a fundamental distinction between these two types of deontics. Ought-to-do deontics are the kind captured in Kratzer's system via a circumstantial modal base (which picks out facts of the base world) and a deontic ordering source. Ought to be deontics, on the other hand, seem to double a modal statement with a performative act, namely, that of putting an obligation on the addressee (cf. Ninan 2005 for such a treatment of deontic 'must'): the babysitter in (21), and perhaps a larger community in (20)a). There is no performative dimension in cases of ought-to-do deontics, which simply describe an obligation on the subject.

Why should such a distinction matter? I would like to show that it is relevant for the actuality entailment pattern. When we turn to modalized constructions other than the standard modal auxiliaries, we see that deontics which involve someone granting permission or putting an obligation on someone else do not yield actuality entailments. In French (and Greek), 'permit' is

\footnotetext{
${ }^{7}$ I am using the ought-to-do/ought-to-be labels to refer to the distinction between the class of deontics that puts an obligation on the subject vs. that which puts an obligation on the addressee. My claims are not about the English modal ought itself, whose own particularities would lead us too far astray (see von Fintel and Iatridou, in progress).
} 
ambiguous between a grant permission reading (22)a), which doesn't yield an actuality entailment; and an enable reading (22)b), which does (S. Iatridou, p.c.):

(22) a. Le doyen m’a permis d'utiliser la bibliothèque, mais je n’y suis pas allée. The dean permitted-pfv me to use the library, but I didn't go.

b. Cette carte m'a permis d'utiliser la bibliothèque, \# mais je n’y suis pas allée. This card permitted-pfv me to use the library, \#but I didn’t go.

(22) suggests that a 'grant permission' deontic doesn't yield actuality entailments. Furthermore, consider the case of the modal être censélêtre supposé (be supposed to), which can only have epistemic/deontic interpretations, but not goal-oriented ones (K. von Fintel, p.c.) (and thus perhaps no circumstantial interpretation at all). As the following example shows, it doesn't yield an actuality entailment with perfective:

(23) ??Kitty a été censée/supposée faire ses devoirs, ${ }^{\circ k}$ mais elle ne les a pas fait. Kitty was-pfv supposed to do her homework, but she didn't do it

Perfective morphology on this modal is almost unacceptable, but to the extent that it is grammatical, it certainly doesn't yield an actuality entailment: the continuation is not contradictory, hence (23) doesn't entail the actualization of its complement.

Turning back to modal auxiliaries, we see that a similar effect arises. Devoir has two kinds of deontic readings: a performative 'grant permission' one, where the speaker grants permission/puts an obligation on the addressee (i.e., addressee-oriented, or ought-to-be deontic); and a more circumstantial deontic one (i.e., subject-oriented, or ought-to-do deontic). To bring out the performative reading, consider a version of the babysitter example, where Kitty's mom comes back and sees that Kitty's homework has been left untouched. She addresses the babysitter ('Congratulations!' helps bring out the performative reading: the speaker performs a congratulatory act to her addressee, here, sarcastically):

??Kitty a dû faire ses devoirs, mais elle ne les a pas fait. Bravo!

Kitty must-pfv do her homework, but she didn't do it. Congratulations!

This is just as odd as (23) is. And the oddity does not come from the fact that the continuation seems contradictory. Even if the mother comes back and sees that the babysitter did her job of ensuring that Kitty did her homework, she cannot say: 
??Kitty a dû faire ses devoirs, et elle les a fait. Bravo!

Kitty must-pfv do her homework, and she did it. Congratulations!

Note that with imperfective aspect, this is fine again (as is the supposed to example):

(26) a. Kitty devait faire ses devoirs, et elle les a fait/mais elle ne les a pas fait (bravo!). Kitty must-imp do his homework, and she did/but she didn't (congratulations!).

b. Kitty était censée faire ses devoirs, et elle les a fait/mais elle ne les a pas fait (bravo!). K. was-impf supposed to do her homework, and she did/but didn't (congratulations!)

There thus seems to be an incompatibility between perfective aspect and performative deontics, which involve putting an obligation on someone else. This can be explained by appealing to the fact that putting an obligation on an addressee after the fact is simply pointless. Indeed, Ninan (2005) argues that it is impossible to request of someone to bring about a past state of affairs. If the mother wanted to scold the babysitter for failing to fill her obligations, she should have used a counterfactual element, either conditionnel (a morpheme used to express counterfactuality), or imperfective (which can also express counterfactuality, as we will see in section 3), as in (26).

To sum up, the modal interpretations that yield actuality entailments are the circumstantial ones: ability, goal-oriented, subject-oriented deontics, and the pure circumstantials ('roots'). Those that do not are the epistemics and addressee-oriented deontics. We further saw that the ones that do not are interpreted above aspect. For epistemics, the aspect that appears on the modal itself is interpreted below it. For addressee-oriented deontics, we saw that perfective was ungrammatical. The reason, I believe, is that tense and aspect are interpreted under the modal (as with epistemics), but the meaning that results is incoherent (unlike epistemics), as it puts a present obligation to bring about a past state of affairs. This suggests that the reason why epistemics and addressee-oriented deontics are immune to actuality entailments is because they are interpreted above aspect. Conversely, circumstantials are interpreted below aspect. In section 2, I will show how to derive actuality entailments, once we assume that those cases involve a configuration where aspect is above the modal.

Why should epistemics and deontics be interpreted above Tense and Aspect? It is a well known fact that epistemics tend to be interpreted higher than 'root' modals: they scope above tense (cf. Iatridou 1990, Abusch 1997, Stowell 2004...), negation (cf. Drubig 2001, Cormack and Smith 2002), and quantifiers (cf. Brennan 1993, von Fintel and Iatridou 2000). To handle 
these facts, it is usually assumed that epistemics are somehow merged high, and roots low (e.g., by having epistemics take propositions as their complements, and roots take properties, cf. Jackendoff 1972, Brennan 1993, Butler 2004, a.o.). In the present paper, I assume that a modal always take a propositional complement, and can freely be merged above or below tense. I however put aside the issue of why a modal merged above tense receives an epistemic (or an addressee-oriented deontic) interpretation, and why a modal merged below tense a circumstantial one (for a proposal of why this should be the case, see Hacquard 2006). The question this paper addresses then, is why a modal merged below tense (which happens to be interpreted as a circumstantial) yield actuality entailments with perfective aspect.

\subsection{HeIGHT OF INTERPRETATION: SyNTAX, MORPHOLOGY AND SCOPE}

Our working hypothesis is that we have a difference in height for the two classes of modal interpretations: one above aspect, one below it. One question is whether we are dealing with a difference in scope or not. Does the final ordering of modals and aspect involve QR (Quantifier Raising)? And if so, is it QR of the modal auxiliaries or that of aspect? Assuming covert movement of modals might have undesirable consequences. We should for instance expect the possibility for inverse scope with two modals in a row, which we do not get (von Fintel and Iatridou 2003). The sentence below cannot mean that Jane had permission to have to watch TV. Note that it isn't a quirk of the periphrastic 'be allowed' to. In the French version of the example, stacking modals yields a fixed order that reflects the surface order:

(27) a. Jane should be allowed to watch TV.

b. Jane doit pouvoir regarder la télé. Jane must can watch TV.

Furthermore, if the movement of the modal were covert, we might not expect a difference between French and Italian. Recall that in French, aspectual morphology on the modal either yields a circumstantial or an epistemic interpretation. In Italian, however, no epistemic interpretation is possible. Instead, aspect needs to be overtly realized on the complement: 
a. Bingley a pu parler à Jane.

[epistemic]

b. *Bingley ha potuto parlare a Jane.

[*epistemic]

Bingley can-pst-pfv talked to Jane.

(29) a. Bingley peut avoir parler à Jane.

b. Bingley può aver parlato a Jane.

Bingley can-pres have talked to Jane.

MOD -T -Asp -VP

I thus propose that the different heights of interpretation result from a different order in overt syntax ${ }^{8}$. In French, the two possible orders 'Tense-Aspect-Modal' and 'Modal-TenseAspect' have (optionally) the same morphological spell-out. Italian, on the other hand, doesn't allow 'Modal-Tense-Aspect' to be spelled out as one morphologically complex unit. I believe that this difference should fall out from morphological constraints. A precise account of what these constraints are is beyond the scope of this paper: e.g., they may involve morphological blocking due to the language-specific assignment of which head (tense or modal or AGR) carries case and agreement features (cf. Giorgi and Pianesi 1997 for a proposal on the morphological constraints on tense). Note that differences in morphological spell out between French and Italian are otherwise attested. Consider the following examples from Kayne (1991). In the infinitives below, Italian shows clitic right-adjunction, while French has clitic left-adjunction:
a. *Parler lui $/{ }^{\text {ok }}$ Lui parler serait une erreur.
b. ${ }^{\text {ok}}$ Parlagli/ *gli parlare sarebbe un errore.
Talk-him/him talk be-cond a mistake
'Talking to him would be a mistake'.

Kayne argues that the clitic right adjunction in Italian results from an extra V-movement. In Italian, it would be necessary for $\mathrm{V}$ to move past adverbs between $\mathrm{T}$ and $\mathrm{I}$, but not in French, a property he links to the null subject parameter. Whatever mechanism is responsible for the difference in (30)a) (e.g., extra verb movement in Italian; 'affix'-lowering allowed in French; case/agreement features) could be connected to the contrast with epistemic modals. At the very least, it indicates that, while the two languages are closely related, their morphological component seems to be subject to different constraints. I leave precise morpho-syntactic details for future research, and simply assume that the differences between French and Italian epistemic

\footnotetext{
${ }^{8}$ Thanks to Alec Marantz for helpful discussion on the topic.
} 
interpretations should result from morphological constraints (which are independently attested), rather than from differences in what can covertly move.

\section{Proposal}

In this section, I will show how to derive an actuality entailment. To make the following discussion easier to follow, I will give the punch line right away. The actuality entailment results from the modal's relative height with respect to aspect: when aspect is above the modal, we get an actuality entailment (provided there is no extra layer of modality above it); when aspect is below it, we don't get an actuality entailment. This is so because, as we will see, aspect comes with its own world argument, which needs to be bound locally. This world argument has to be bound by a modal immediately above it, but cannot be bound by that modal, if the modal is below it. In that case it has to be bound by whatever mechanism is responsible for defaulting to the actual world in matrix contexts (e.g., explicit binders in the syntax, à la Percus 2000). When the world argument of aspect is the actual world, it yields an actual event (provided, again, that there is no extra layer of modality, as I argue is the case for the imperfective).

\subsection{AsSumPTIONS: TENSE AND ASPECT}

Before going into the specifics of how this is done, I will first make explicit my assumptions for the semantics of tense and aspect.

\subsubsection{Tense and world pronouns}

There are many ways that tense could be encoded in the grammar, and both the linguistic and the philosophical literature is very rich on the topic. In classic accounts of tense in the Prior and Montague tradition, times are manipulated in the meta-language. Each lexical item is evaluated w.r.t. to a time (on top of a world) parameter, which can be manipulated by tense operators (PRESENT or PAST). Thus, PAST has the following semantics:

$$
[[\text { PAST } \phi]]^{\mathrm{g}, \mathrm{t}, \mathrm{w}}=1 \text { iff there is a time t' s.t. } \mathrm{t}^{\prime}<\mathrm{t} \& \phi\left(\mathrm{t}^{\prime}\right)=1
$$

More recently, however, there has been a trend to move away from treating Tense and Mood as sentential operators, but rather to have explicit quantification in the syntax (cf. e.g., Kusumoto 2002 for more details). Partee (1973) first pointed out that a more adequate theory of tense should treat tenses as pronouns, or variables, on a par with individuals. This move rests on 
arguments that tenses have all of the uses that individual pronouns do, and thus, should receive a similar analysis. For instance, the sentence below shows that we can refer deictically to a time interval (the same way 'he' or 'she' can refer deictically to someone), and that, moreover, an operator-type analysis of tense is inadequate for such cases:

(32) I didn't turn off the stone.

[Partee (1973)]

(32) doesn't mean 'at no time prior to the utterance did I turn off the stove', which is obviously false, nor the trivially true 'there is some point in the past where I did not turn off the stone'. Instead, the most straightforward reading of (32) is that there is a salient past interval (e.g., right before I left my house) where I didn't turn off the stove. Stone (1997) argues that, similarly, mood has some deictic uses as well. In the following example, we're referring to those worlds in which my friend turns the music up:

(33) [To a friend who’s about to turn the music up] My neighbors would be very upset.

These sorts of examples argue away from treating worlds and times as mere parameters, but rather to have them explicitly represented: like pronouns, they can have indexicals, anaphoric or bound variable uses (cf. Kratzer 1998, Schlenker 2002, a.o.). At the very least, there seem to be compelling reasons to move away from operator-like analyses of tense and mood, where a tense/modal operator will blindly give a value to any time or world variable in its scope, and to have a more unified account of quantification across domains.

Following Partee (1973), Kratzer (1998), a. o., I will assume a referential analysis of tense, where tenses are pronouns. They combine with predicates of times, the same way an individual pronoun combines with a predicate of individuals. In Kratzer's system, the two main tenses are indexical pronouns (present and past):

(34) a. [[pres] $]^{\mathrm{g}, \mathrm{c}}$ only defined if c provides an interval $\mathrm{t} \approx \mathrm{t}_{0}$ (speech time). If defined $[[\text { pres }]]^{\mathrm{g}, \mathrm{c}}=\mathrm{t}$.

b. [[past] $]^{\mathrm{g}, \mathrm{c}}$ only defined if c provides an interval $\mathrm{t}<\mathrm{t}_{0}$ (speech time). If defined $[[\text { past }]]^{\mathrm{g}, \mathrm{c}}=\mathrm{t}$.

Note that the overlap/anteriority relation w.r.t. the utterance time of the tenses is given by a presupposition. Anaphoric tenses (or zero tenses, in Kratzer's terminology) will arise in cases of 
embedding under attitude verbs. 'Zero tenses are lexically indexed variables that have no presuppositions and must be bound by a local antecedent' (e.g., a pres or a past):

$$
\text { a. }\left[\left[\varnothing_{n}\right]\right]^{g, c}=g(n)
$$

Similarly for worlds. Percus (2000) argues that there are explicit world pronouns (situation pronouns in his framework) in the syntax, and that these pronouns need to be bound. In matrix context, he assumes a topmost default world binder, which maps to the actual world. Other binders include those introduced by attitude verbs or adverbs of quantification. I will follow Percus' two assumptions, namely that (i) there are explicit world variables represented in the syntax (rather than relying on a world parameter in the index), and (ii) the binding of these variables obey strict locality conditions: they need to be bound by a matrix binder or a closer binder when available.

\subsubsection{Aspect}

We will thus treat tenses and worlds as pronouns, on a par with individuals. What about aspect? What role does it play? What does it manipulate? In order to account for aspectual properties of natural language, one needs to assume, at the very least, a notion of time intervals which can overlap, be sequential, etc. A more elegant, and perhaps more intuitive way to encode these aspectual properties is to assume an extra entity in our ontology, namely events. We see that tenses refer to times: they are pronouns, which combine with predicates of times. Similarly, we will have events, which will combine with predicates of events. The role of aspect will be to take predicates of events and return predicates of times, which, in turn will combine with tenses.

\subsubsection{Events}

While finding a precise definition for what an event is has proven to be a rather difficult task (as we will see in section 2.3), events themselves are a very intuitive notion. The layman will easily conceive of drinking a cup of coffee or reading a paper or getting a $3^{\text {rd }}$ degree burn as selfcontained units, which can be repeated, or overlap, or enter into causal relations. And indeed, our conception of events mimics closely our conception of objects: we can see (an event of) Jane crossing the street, just like we can see a table in front of us; we can drink a cup of coffee again, just like we can drink another cup of coffee. A crucial argument for actually representing events 
in natural language was put forward by Davidson (1967), and involves entailment patterns between sentences, such as the ones below:

(36) a. Brutus killed Caesar.

b. $\exists e[$ kill(e) \& Agent(e,C.) \& Theme(e,B.)

c. Brutus killed Caesar with a knive.

d. $\exists e[$ kill(e) \& Agent(e,C.) \& Theme(e,B.) \& Instrument(e, knife)

If events were not represented, we would have no straight-forward way of deriving the asymmetric entailment from (c) to (a), as the two predicates kill and kill with a knife, would be independent from one another. Once we have events, however, we clearly see how (d) entails (b), but not vice versa.

Since Davidson's work, then, it has become rather standard to assume that predicates take an event or situation argument (roughly defined as a spatio-temporal slice). In other words, VPs are predicates of events:
a. $[[\mathrm{VP}]]=\lambda \mathrm{e} \cdot \mathrm{P}(\mathrm{e})$
b. $[[$ rain $]]=\lambda$ e. $\operatorname{rain}(\mathrm{e})$

Where does that leave individual arguments? For concreteness purposes, I chose assumptions which I won't motivate, for reasons of space (I refer the interested reader to Kratzer 1996). For Davidson, a predicate like kill is a 3-place predicate: it takes an event, an agent, and a theme. Neo-Davidsonians have argued that each argument has to be introduced separately, the way it is represented in (36). I will assume, following Kratzer (1996), that there is an asymmetry between the internal and the external argument of a verb (cf. also Marantz 1984), such that the object and the event should be arguments of the verb itself, while the external argument should be introduced by a separate voice projection. What sits in voice is an Agent relation, for eventive predicates, or an Experiencer relation for stative predicates. The VP and the agent combine through an operation of Event Identification, and return a predicate of events:
a. $[[$ kill $]]=\lambda x \lambda e \cdot \operatorname{kill}(\mathrm{x})(\mathrm{e})$
b. $\quad[$ kill the dog] $=\lambda$ e. $\operatorname{kill}($ the $\operatorname{dog})(\mathrm{e})$
c. $\quad[$ Agent] $]=\lambda e \lambda x$. Agent $(x)(e)$ 
d.

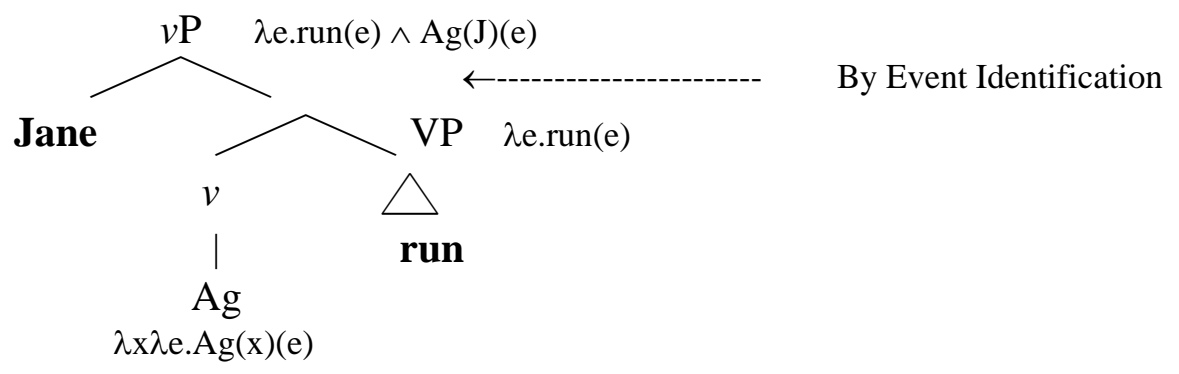

At the vP level, we then have a predicate of events, which needs to combine with an event. As we will see in the next section, this is where aspect comes in: Aspect is a quantifier over events, which takes a predicate of events, and turns it into a predicate of times. The predicate of times can then combine with a tense.

\subsubsection{Aspect}

The primary function of aspect is to quantify over event variables, and transform a predicate of events into a predicate of times. Differences between the various aspects have to do with the durational properties of these events. Intuitively, progressive/imperfective aspect (b) 'streches' an event so that the duration of that event surrounds a reference time, while a perfective (a) 'squeezes' an event inside a reference time:

a. Yesterday afternoon, Jane read a book.

b. Yesterday afternoon, Jane was reading a book.

In (a) the running time of Jane reading a book is contained within yesterday afternoon, whereas in (b) it surrounds yesterday afternoon. Thus, for (a) to be true, Jane must have finished her book yesterday afternoon, but no such requirement holds for (b).

More formally, it has been assumed that perfective and imperfective aspects both existential quantify over the event variable and locate the temporal trace of the event $(\tau(\mathrm{e})$, following Krifka, 1992) with respect to the evaluation time given by tense. The difference between the two aspects is that perfective locates the time of the event within the reference time, while imperfective locates the reference time within the event time (cf. Klein 1994). As a starting point, I will use the following lexical entries (from Kratzer 1998):
a. $\quad[[$ PERFECTIVE $]]=\lambda \mathrm{P} \cdot \lambda \mathrm{t} \cdot \lambda \mathrm{w} \cdot \exists \mathrm{e}[\tau(\mathrm{e}) \subseteq \mathrm{t} \& \mathrm{P}(\mathrm{e})(\mathrm{w})=1]$
b. $\quad[[$ IMPERFECTIVE $]]=\lambda \mathrm{P} \cdot \lambda \mathrm{t} \cdot \lambda \mathrm{w} \cdot \exists \mathrm{e}[\mathrm{t} \subseteq \tau(\mathrm{e}) \& \mathrm{P}(\mathrm{e})(\mathrm{w})=1]$ 
(41) illustrates the combination between the two aspects and the predicate of events rain. Recall that I assume an indexical role for tense which orders the evaluation time with respect to the utterance time (past needs a time that precedes the utterance time, present, one that overlaps with it), through a presupposition (indicated within curly brackets):
a. Il a plu.
It rained-pfv
$\exists \mathrm{e}\left[\tau(\mathrm{e}) \subseteq \mathrm{t}\left\{\mathrm{t}<\mathrm{t}^{*}\right\} \&\right.$ rain $\left.\left(\mathrm{e}, \mathrm{w}^{*}\right)\right]$
b. Il pleuvait.
It rained-impf
$\exists \mathrm{e}\left[\mathrm{t} \subseteq \tau(\mathrm{e})\left\{\mathrm{t}<\mathrm{t}^{*}\right\} \&\right.$ rain $\left.\left(\mathrm{e}, \mathrm{w}^{*}\right)\right]$

It is assumed, traditionally, that the aspect projection is base-generated under tense, and binds event variables in its scope. Thus a verb would have a free event argument that would get bound by the aspect above it. However, I would like to explore an alternative to this view (suggested in lecture notes by von Fintel, 2001), namely that aspect is directly base generated as an argument of the verb. Being of the higher quantifier type, aspect will then move out of this position and leave a trace of type $\varepsilon$ (for eventualities), which it will bind from its target position, the same way a quantifier over individuals in object position moves up and leaves a trace of type e. Aspect is thus a quantifier of type $\langle<\varepsilon t,>,<\mathrm{i}, \mathrm{t}>>$ : it first moves out of its base position and then moves right below tense, in order to combine with a time argument (of type $<\mathrm{i}>$ ), to finally return a truth value (ignoring worlds for the moment):

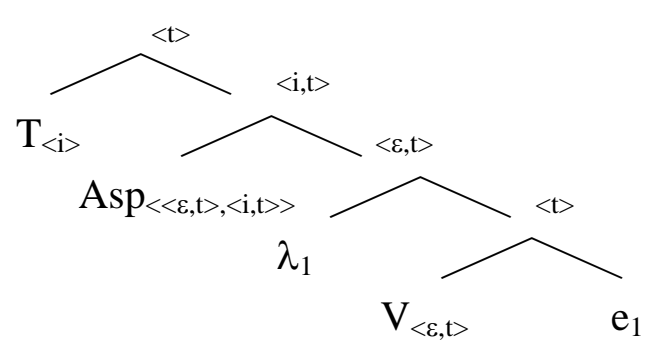

In simple cases, the two options will be equivalent, and the quantifier movement's appeal might then be purely esthetic, as it maintains a parallel between quantification over events and quantification over individuals. However, if a modal intervene between tense and aspect, the 
quantifier movement approach allows aspect to move above the modal and bind the event argument (its trace) below the modal quite naturally ${ }^{9}$ :

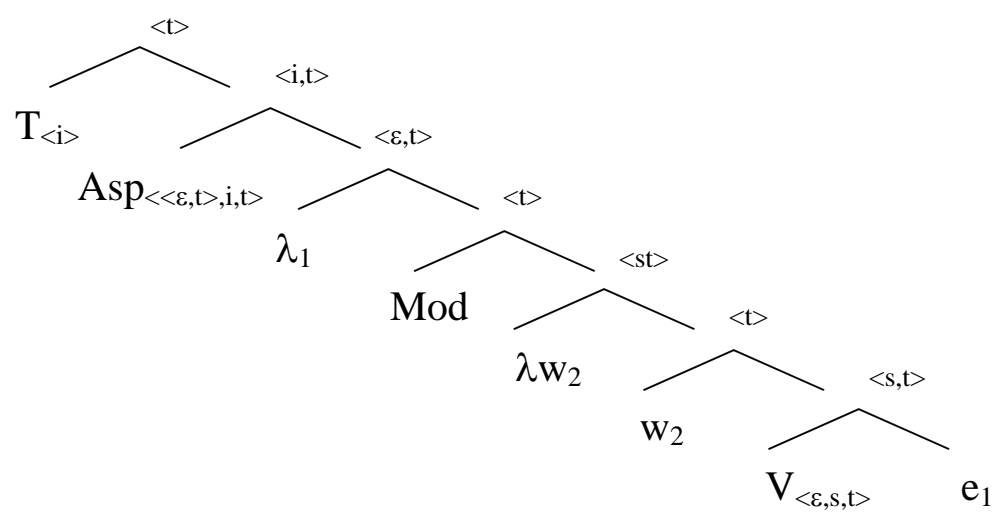

An additional assumption will allow us to derive the actuality entailment quite naturally: Aspect takes a world argument in its restriction, as well as in its scope, again paralleling quantifiers over individuals. And, as for quantifiers over individuals, the two world arguments may be bound by different binders. Consider the following example from Percus (2000):

If every semanticist owned a villa in Tuscany, what a joy it would be.

The sentence in (44) is ambiguous between two readings: the 'transparent' reading asserts that all of the worlds in which every current/actual semanticist owns a villa in Tuscany are happy worlds (two different world indices). The 'opaque' reading states that all of the worlds where every semanticist in those worlds own a villa are happy worlds (same world indices). In other words, the world argument associated with the NP semanticist can either be the actual world, or the world being quantified over in the would-conditional. In order to capture this, Percus argues that there are explicit world variables, which need to be bound, either by a default binder in a matrix context that maps to the actual world, or by a binder provided by e.g., a modal. Percus further claims that these binding possibilities obey some binding principles, which differentiates between the world variable inside the restriction of a quantifier like every (in our example [semanticist in $\mathbf{w}$ ]), and the world variable inside its scope (here [own a villa in $\mathbf{w}$ ]). While the

\footnotetext{
${ }^{9}$ Note that we could take this proposal one step further by assuming that tenses are also quantifiers merged as argument of aspect, which in turn have to move for type reasons. One more step would have modals (quantifiers over worlds) merge as arguments of tense (cf. von Fintel 2001), and also move for type reasons. For reasons of space and time, I won’t pursue this option further, and leave it open for future research.
} 
former can be bound by either by the matrix binder (yielding actual semanticists), or by the binder provided by would (yielding semanticists in the counterfactual worlds), the binding of the world variable inside the scope of the quantifier seems to obey some strict locality principle: it has to be bound by the closest binder. In the above example, this is the binder provided by would $\left(\lambda_{1}\right)$. This binding principle prevents unattested readings of (44) where we talk about semanticists in the counterfactual worlds (or in the actual world), owning villas in the actual world:
a. $\lambda_{0}$ [IP1 if [IP2 $\lambda_{1}$ [IP3 [every semanticist $\mathbf{w}_{\mathbf{0}}$ ] own-villa $\mathbf{w}_{\mathbf{1}}$ ] what a joy]
b. $\lambda_{0}$ [IP1 if [IP2 $\lambda_{1}$ [IP3 [every semanticist $\mathbf{w}_{\mathbf{1}}$ ] own-villa $\mathbf{w}_{\mathbf{1}}$ ] what a joy]
c. $* \lambda_{0}$ [IP1 if [IP2 $\lambda_{1}$ [IP3 [every semanticist $\mathbf{w}_{\mathbf{0}}$ ] own-villa $\mathbf{w}_{\mathbf{0}}$ ] what a joy]
d. $* \lambda_{0}\left[\mathrm{IP} 1\right.$ if [IP2 $\lambda_{1}$ [IP3 [every semanticist $\mathbf{w}_{\mathbf{1}}$ ] own-villa $\mathbf{w}_{\mathbf{0}}$ ] what a joy]

Going back to aspect, I would like to argue for a similar architecture. Aspects are quantifiers over events: they have a world pronoun in their restriction. I therefore propose to modify Kratzer's entries as follows. (Note that the world argument in the scope of aspect will come from the predicate of events):
a. $[$ [PERfective $]]=\lambda \mathrm{w} \cdot \lambda \mathrm{t} \cdot \lambda \mathrm{P}_{<\varepsilon \mathrm{t}>} \cdot \exists \mathrm{e}[\mathrm{e} \text { is in } \mathrm{w} \& \tau(\mathrm{e}) \subseteq \mathrm{t} \& \& \mathrm{P}(\mathrm{e})=1]^{10}$
b. $\quad[[$ IMPERFECTIVE $]]=\lambda \mathrm{w} . \lambda \mathrm{t} . \lambda \mathrm{P}_{<\varepsilon t>} . \exists \mathrm{e}[\mathrm{e}$ is in $\mathrm{w} \& \mathrm{t} \subseteq \tau(\mathrm{e}) \& \mathrm{P}(\mathrm{e})=1]$

These lexical entries differ from Kratzer in two respects: (i) the order of arguments and (ii) where the world anchoring happens. Let's put all of the pieces together in a simple example to illustrate. Recall that I follow Percus (2000) in assuming overt world pronouns in the syntax:
a. Il a plu.
It rained-pfv

\footnotetext{
${ }^{10}$ In her analysis of counterfactuals, Arregui (2005) gives an interesting proposal for perfective aspect, which could perhaps be used in alternative to the present account of the perfective. For her, perfective is a deictic (default) aspect, which introduces a free event variable (as opposed to the perfect, which, in her account, is a quantifier over events). The denotation of this variable is an actual world event that fits the description given by the VP.

(i) $\quad\left[\left[\varnothing_{\text {perfective }}-\mathbf{e}\right]\right]^{\mathrm{g}}(\mathrm{P})=\lambda \mathrm{t} \lambda \mathrm{w}[\mathrm{P}(\mathrm{g}(\mathbf{e}))(\mathrm{w}) \& \tau(\mathrm{g}(\mathbf{e})) \subset \mathrm{t}]$

One potential issue for Arregui's perfective is that under attitudes, a perfective doesn't yield an actual event of any kind. Note that the presence of the time adverbial prevents us from saying that it is a Kratzerian (1998) perfect:

(ii) Jane pense que Bingley a pris le train à 3 heures.

Jane thinks that Bingley took-pfv the train at 3:00pm
} 
b.

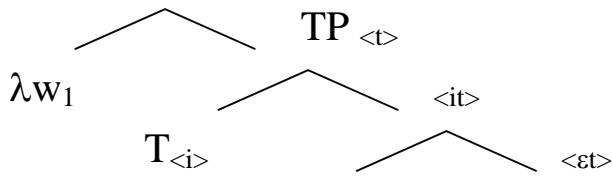

Pst $\operatorname{Asp}_{<<\varepsilon t>,\langle i t>>} \mathrm{VP}_{<\mathrm{t}\rangle}$

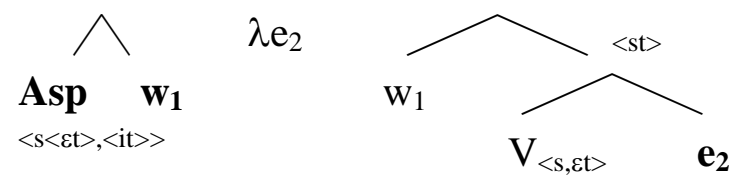

rain

c. $\exists e\left[e\right.$ in $\left.\mathrm{w}^{*} \& \tau(\mathrm{e}) \subseteq \mathrm{t}\left\{\mathrm{t}<\mathrm{t}^{*}\right\} \& \operatorname{rain}(\mathrm{e})\right]$

Aspect takes a world, a predicate of events, and a time. In the above example, the only world binder is the one provided by the syntax; both world pronouns get bound by it. In such simple cases, having the world argument in the restriction will be indiscernible from not having it (as in the Kratzer version). However, as we will see shortly, when the aspect moves above a modal element, the world variable in its scope will have to be bound by the binder provided by that modal element, while that of the restriction will have to be bound by a higher (matrix) binder (as would be the case for (43)). If this right, we then observe a crucial difference in the binding conditions that apply to quantifiers over events vs. quantifiers over individuals: it appears that the world argument of the event quantifier's restriction also obeys some locality principle, and thus needs to be bound by its closest binder. This is a welcome result. Percus formulates his binding principles on a construction by construction basis. The further constraint we see here suggests that we could in fact reformulate Percus's binding principles in terms of a more general condition, stating that any world argument on the 'spine' of the tree ( $\mathrm{T}, \mathrm{A}, \mathrm{M}, \mathrm{V})$ needs to be bound by the closest binder (K. von Fintel, p.c.).

Giving aspect a world argument has precedence in the literature. Landman (1992)'s analysis of the progressive essentially anchors an event to a world (the actual world in matrix contexts). According to Landman's analysis, in a progressive statement such as 'Jane is crossing the street', there is an extensional element, namely an event $e$ in the actual world which corresponds to a beginning stage of a larger event, which in some continuation branch (in some possible worlds) is the completed event of crossing-the-street. One way of recasting Landman's account to fit the current framework is to say that the 'extensional' component takes a world pronoun, which, in matrix context is bound by a default binder (à la Percus). 
I have argued that event quantification should be amenable to an analysis which closely matches that of quantification over individuals: There are generalized quantifiers over events, which work in a similar fashion as generalized quantifiers over individuals. Verbs select for an event argument. When this event argument is a quantifier, the quantifier needs to move for type reasons to a position right below $\mathrm{T}$. I assume that the syntax allows free merging order of $\mathrm{T}$ and Mod (the default hypothesis); when $\mathrm{T}$ is merged above Mod, then aspect will have to move above the modal, if $\mathrm{T}$ is merged below Mod, then Aspect will move right below T, but it won't move above the modal. This is, at least, what happens for perfective aspect. So far, I have assumed an analysis of the imperfective which closely matches that of the perfective, modulo the direction of the inclusion relation w.r.t. reference time. As we will see in section 3, the semantics of the imperfective may be more involved. Indeed, imperfective covers a wide range of cases: progressive, habituals, counterfactuals, generics, and it is not clear that we can find a single lexical entry for all of these uses. The one in (46)b) is most probably an unlikely candidate.

To sum up, the two crucial assumptions I am making are (i) aspect is anchored to a world (via a world pronoun that has to be bound); (ii) aspect has to move from its base-generated position as an argument of the verb for type reasons. This movement can target a position above the VP or above the modalP (depending on where $\mathrm{T}$ is w.r.t. a modal). In the case of the latter, the aspect's event argument will have to be bound by the default matrix binder, forcing the event to be part of the actual world.

One final remark. In this section I have tried to push the parallel between events and individuals and to standardize quantification. However, the analogy breaks down in the syntactic assumptions required for each. While quantifiers over individuals move for type reasons, they do so covertly, via Quantifier Raising (QR):

Some boy insulted every girl.

To get inverse scope (i.e., for every girl, there is a (different) boy who insulted them), it is assumed that every girl moves covertly to a position where it has scope over some boy. In the event domain, however, I take aspect to move overtly. 


\subsection{DERIVING THE IMPLICATIVE READING OF ROOT MODALS}

Taking stock of what we have so far: The different interpretations of modal auxiliaries share a semantic core: they involve the same lexical items (cf. Kratzer 1981, 1991), and their differences arise from a combination of contextual and structural factors. What is crucial for this section is that only root modals scope under aspect, and hence yield actuality entailments. Perfective aspect is a quantifier over events; it is base-generated as an argument of the verb, a position from which it needs to move out of for type reasons. When it moves above the modal, it yields an actuality entailment. Let's see how:

a. Jane could-pfv run

b.

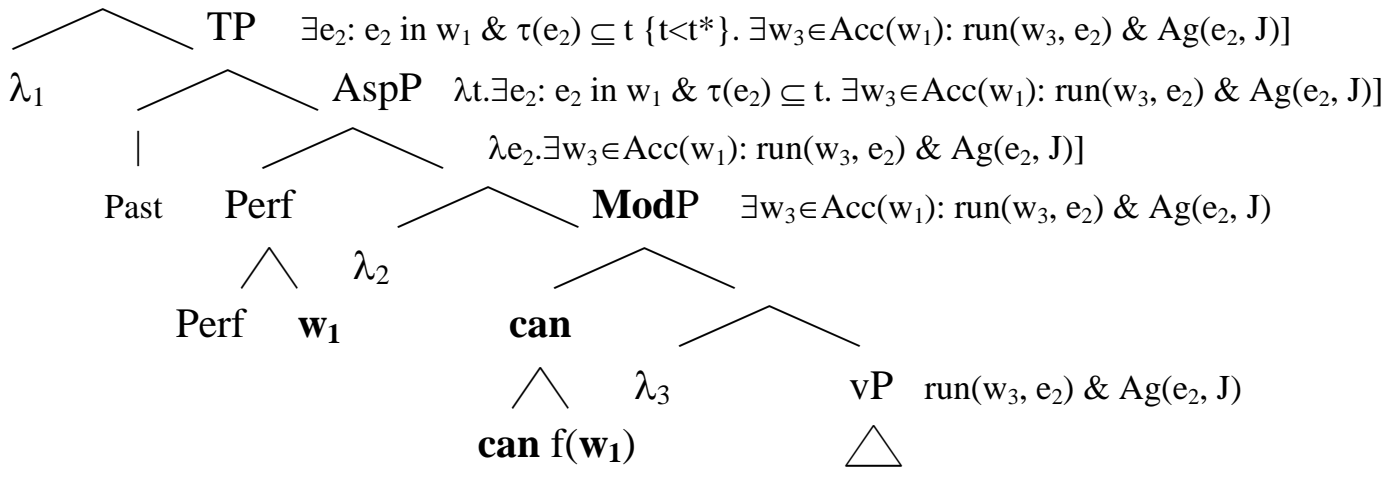

Jane run $\mathrm{e}_{2} \mathrm{w}_{3}$

c. $\exists \mathrm{e}_{2}\left[\mathrm{e}_{2}\right.$ in $\left.\mathrm{w}_{1} \& \tau\left(\mathrm{e}_{2}\right) \subseteq \mathrm{t}\left\{\mathrm{t}<\mathrm{t}^{*}\right\} . \exists \mathrm{w}_{3} \in \operatorname{Acc}\left(\mathrm{w}_{1}\right): \operatorname{run}\left(\mathrm{w}_{3}, \mathrm{e}_{2}\right) \& \operatorname{Ag}\left(\mathrm{e}_{2}, \mathrm{~J}.\right)\right]$

'There is an event in $w^{*}$ located in a past interval, and there is a world compatible with $J$.'s abilities in $w^{*}$ where that event is a running event by $J$. '

Perfective aspect is base-generated as an argument of the verb, but needs to move out to combine with a time pronoun sitting in Tense. In the above case, it moves above the modal. There are two world binders in the structure, the one introduced by the modal $\left(\lambda_{3}\right)$ and the default matrix one $\left(\lambda_{1}\right)$, following Percus (2000). The world argument of the perfective has no choice but to be bound by the latter, given that it is above the modal. This will yield an actual event, which in some possible world is a running event by Jane.

What is this actual event? We know from the way it is bound that it is the same event in $\mathrm{w}_{3}$ as in $\mathrm{w}_{1}$. This is not enough. How does the inference that Jane ran in the actual world come about? Or, in other words, how is it that we (speakers of French and Italian) take the event in the actual world, which is a running event in some world, to be a running event in the actual world as well? Basically, events have some essential properties that they share across worlds. What 
these essential properties are will be whatever properties allow us to identify the event as a running event in the first place. Because it has these properties in some world, it will have these properties in all of the worlds in which it occurs, and thus, crucially, in the actual world. We will hence have to identify it as a running event in the actual world. If a (complete) event is a P-event in a given world, then in every world in which it occurs (in its entirety), it will be a P-event there as well. I will thus argue for a principle of event identification across worlds:

Event Identification across Worlds (version 1):
For any $w_{1}, w_{2}:$ If an event $e$ occurs in $w_{1}$ and $w_{2}$,
and $e$ is identifiable as a P-event in $w_{1}$,
it will be identifiable as a P-event in $w_{2}$ as well.

The actuality entailment comes about as follows: In (49), we know that $\mathrm{e}_{2}$ occurs in $\mathrm{w}^{*}$ (the event is bound in the actual world). We further know that $\mathrm{e}_{2}$ is a running event in some world w. We therefore conclude that $\mathrm{e}_{2}$ is a running event in $\mathrm{w}^{*}$ (given (50)). The prediction that this account makes then is that because (i) existential closure is outside of the scope of modal, and (ii) events retain their essential properties across worlds, whenever aspect scopes over the modal, we should get actuality entailments ${ }^{11}$. The question will then become where do the non implicative readings with imperfective come from, a question to which we will return in section 3. In the next section, I would briefly like to address the matter of cross-world identity.

\subsection{EVENT IDENTIFICATION ACROSS WORLDS}

As we saw in section 2.1, postulating events in one's ontology has been an intuition-friendly device to handle entailment patterns from sentences such as Brutus killed Caesar with a knife to Brutus killed Caesar (cf. Davidson 1967). Although events are a very intuitive notion, their characterization turns out to be very difficult to pin point. Adding events in the ontology faces important philosophical questions. What kind of entities are they? Do they differ from material objects? Are events particulars or universals? Concrete or abstract? What are their identity and identification criteria? What is their place in a causal network (Pianesi and Varzi, 2000)? The main challenge for a theory of events is to give an identity condition on events: when will two events be the same event?

\footnotetext{
${ }^{11}$ These two crucial ingredients for deriving actuality entailments originated from suggestions by Irene Heim, pc.
} 
Davidson's original theory was that two events are identical if they have the same causes and effects. However, the circularity of this definition led him to ultimately reject it: what are causes and effects if not events? Siding with Quine, he then proposed that events are identical if and only if they occur in the same space at the same time. One major problem with this account arises with the following kind of example. Imagine a sphere which is rotating and heating up at the same time: the heating and rotating of the sphere completely overlap in time and space, but yet our intuitions tell us that we are dealing with two events and not just one. Lewis' proposal (1986) doesn't suffer from this problem: His definition of an event is that it is an event only if it is a class of spatio-temporal regions both this-worldly (assuming it occurs in the actual world) and other-worldly. This handles the heating and spinning problem since the cross-world spatiotemporal profile of the two events is not identical: even if in some world, the heating and spinning occur in the same location, there is a world in which there is heating but not spinning on one location (the spinning will be at another location), and so they aren't the same event.

Note that definitions of event identity really concerns events occurring in the same world: in Lewis' account, if there is an event $\mathrm{e}_{1}$ of running in world $\mathrm{A}$ but that in another world $\mathrm{B}$, there is no running, but only walking, $\mathrm{e}_{1}$ just won't occur in B (or rather, there won't be counterparts of $\mathrm{e}_{1}$ in $\mathrm{B}$ ). However, if (counterparts of) the same event occur across two worlds, then we expect that they will have the same essential/defining properties in both worlds. This is the notion I am appealing to in this account: if an event $\mathrm{e}_{1}$ is a running event in world $\mathrm{A}$, then in all of the worlds in which it will occur, it will be a running event there as well.

Linguists may not be as bothered as philosophers by the spinning and heating example: why not say that the spinning and heating are the same event? Portner (1998) for instance, argues in his analysis of the progressive that Jane crossing the street and Jane walking into the path of an incoming bus are the same event, under two different descriptions. But this may simply be a matter of opinion. From a more linguistic point of view, it seems that the notion of telicity applies to properties of events, and not to events themselves (K. von Fintel, p.c.): Imagine that Jane is walking to school and reaches the school, and that the whole process takes 10 minutes. Arguably, walking to school and walking for 10 minutes are a single event. However, walk to school is telic, but walk for 10 minutes isn't. But then again, we could say that we are dealing with two events, with different cross-world profiles: in some worlds, Jane may have walked for 10 minutes without reaching the school, while in some others she may have walked to 
school, but it would have taken her half an hour. The first event would be atelic, the second telic. It may be very difficult to decide between the two possibilities. If indeed, in these cases, we are dealing with a single event, which can be described as a $\mathrm{P}_{1}$ event (e.g., crossing-the-street) or as a $\mathrm{P}_{2}$ event (e.g., walking-into-the-path-of-a-bus), we may need to reformulate our event identification principle, in a way that won't prevent 'actuality entailments'. One possibility is that, everything else being equal, if an event happens in two worlds, and its properties are such that we 'label' it as a $\mathrm{P}$ event in $\mathrm{w}_{1}$, then, everything else being equal, we will label it as a $\mathrm{P}$ event in $\mathrm{w}_{2}$ as well.

What do I mean by everything else being equal? We just saw instances where, it is arguably possible to give the same event two different descriptions (and thus assign them different properties). This raises the further question of which properties are essential (i.e., underlyingly present in both descriptions of the same event), and which aren't. This is a very difficult metaphysical question. Many philosophers express skepticism about the possibility of identity across possible worlds. Chisholm (2002) for instance discusses an example where we take an individual, say Adam, in our world, and change him very slightly in world 2, for instance, take out one of his hair. Presumably, he remains the same person in both worlds. But, once we accept this and because of transitivity of identity, we're led to accept that Adam is Noah and Noah is Adam, after both undergo a series of slight (unperceivable) changes of their properties until Adam becomes Noah and Noah becomes Adam in a particular world. Chisholm argues that the only way to 'countenance identity through possible worlds and avoid such extreme conclusions is to appeal to some version of the doctrine that individual things have essential properties'. The problem with such a move, Chisholm argues, is that we have absolutely no way of finding out what these properties are, nor even figure out whether an individual has essential properties at all, so why should we assume that he does?

It might, indeed, prove to be a very difficult task to identify precisely which property of an event, or of an individual for that matter, is essential. However, we can at least acknowledge that there is something, call it essential property or something else, which enable us to 'label' this event: it is whatever allows us to agree in most cases to call a running event a running event.

Still, there are cases where we do disagree or misidentify events. Consider the following:

Bill mistakenly thought that Mary’s wedding was a funeral.

[Kai von Fintel, p.c.] 
A comparison with objects is in order. One way to interpret my proposal is to say that I am treating the event de re: the event is somehow both outside and inside the modal. What we learn from de re interpretations of objects/individuals is that they can be thought of in many different guises. We know that a sentence like Darcy wants to marry a plumber is ambiguous. Either Darcy wants to marry someone or other who is a plumber (the de dicto reading). Or, Darcy is in love with a particular person, say Lizzie, who happens to be a plumber (the de re reading). This de re reading is true even if Darcy, in fact, thinks that Lizzie is a pianist. The property that allows us to identify Lizzie in the actual world is 'being a plumber', but she doesn't have to be one in any of Darcy's thoughts. Now, if events also come in many different guises, how could we possibly force them to keep the same description across worlds, which is what we need to derive actuality entailments? This is where, I think, the modality involved plays a role. The de re multitude of guises issue comes about with those attitudes or modals which bring with them the perspective (epistemic state) of someone other than the speaker (e.g., the attitude holder). With root modals, however, the epistemic state of the subject doesn't enter the equation. In the sentence 'Darcy can impress a plumber' (with 'a plumber' interpreted de re), it doesn't matter if Darcy thinks he is trying to impress a pianist. The sentence will be judge true if it is demonstrated that Darcy can in fact impress an actual plumber.

Going back to our event identification principle, we see that, so far, we have been looking at actuality entailments with root modals. Given that the subject's perspective is inconsequential, we can safely assume that the same event will keep the same guise (which is ascribed by the same person, at the same time, in the same world-the speaker at $t^{*}$ in $\mathrm{w}^{*}$ ) across different worlds; there is no change in perspective. Enters Italian want (volere), which, unlike its French and English counterpart) yields actuality entailments with perfective aspect:

(52) Jane ha voluto parlare a Elisabeth, \#ma non lo ha fatto.

Jane wanted-pfv talk to Elisabeth, \# but she didn’t do it

In Hacquard (2006), I propose an analysis for volere similar to the one here for root modals. Notably, I treat volere as a modal, which allows Aspect to move above it, from its base position in the complement, to the matrix $\mathrm{T}$ above volere. Aspect thus binds its trace across the modal element, anchoring the event in the actual world. One crucial difference with root modals is that the modal base involved with want is fixed and picks out the belief-worlds of the subject 
(further ordered by his desires) (cf. Heim 1992, von Fintel 1999). Interestingly, with want, we are able to build scenarios where the same event doesn't receive the same description in the actual world, as it does in the subject's belief worlds. Imagine that Darcy's dream has always been to marry a billionaire. However, upon seeing Jane rummaging through his garbage, he is struck with love; a couple of weeks later, he proposes, despite thinking that she is a homeless person, and they get married. Unbeknownst to him, Jane is of course an eccentric billionaire, who likes to go through trash. Jane is a billionaire in the actual world, but a homeless person in all of Darcy's belief/desire worlds. In English (and in French), there are two ways to report the situation (after his falling in love with Jane). In (a) below, Darcy wants to marry Jane, who he mistakenly takes to be a homeless person. In (b), the billionaire is read de re: Darcy wants to marry Jane, who happens to be a billionaire in the actual world:

(53) a. Darcy wanted to marry a homeless person.

b. Darcy wanted to marry a billionaire.

Once we turn to volere with perfective, we see that (i) we get an actuality entailment (there was a marrying event by Darcy); (ii) the reading in (b) is blocked:

(54) a. Darcy ha voluto sposare una barbona. Darcy want-pfv marry a homeless person

b. \# Darcy ha voluto sposare una milliardaria. Darcy want-pfv marry a billionaire

What's interesting for our purposes here, is that the event description is not the same in Darcy's belief/desire worlds - where it is a marry a homeless person event—as it is in the actual worldwhere it is a marry a billionaire event. In this case, the description of the event in the belief worlds prevails. So here we have a case where our event identity principle runs into a dilemma. How does it get resolved? The truth conditions for (54)a) are as follows: there was an event in the actual world, such that in all of Darcy's belief worlds, it is a marrying a homeless person event. What is this actual event? It is still a marrying event by Darcy, of a person, Jane (which he happens to think is a homeless person). We copy as much of the event description into the actual world as our information permits us. 
Importantly, with a root modal, the identification principle behaves differently. With a circumstantial modal base, the subject's beliefs don't enter the equation. Thus, with the above scenario, only the marry a billionaire event can be reported with a perfective root modal:
a. \#Darcy a pu épouser une clocharde.
Darcy could-pfv marry a homeless person
b. Darcy a pu épouser une milliardaire.
Darcy could-pfv marry a billionaire
c. 'There is an actual event, which in some world compatible with the facts and circumstances in $w^{*}$ is a marrying a billionaire event.'

In all circumstantially accessible worlds, Jane is a billionaire, and so is she in the actual world, it is a fact of the base world. Darcy's beliefs are not factored in.

To sum up, in most cases of actuality entailment, we will infer that the actual event shares all of the properties associated with its description in the accessible worlds, except in cases where the information in those worlds clashes with what we have in the actual world. These cases won't come up with circumstantial modals, given that the circumstances of the events will be the same, including properties of the subject and the object.

Thus the principle of event identification underlying actuality entailments could be recast as the inference mechanism below. This version will only matter in cases where the modal base is not realistic:

\section{(56) Event Identification Across Worlds (version 2):}

For any $w_{1}, w_{2}$ : If an event $e$ occurs in $w_{1}$ and $w_{2}$, and $e$ is described as a P event in $w_{1}$ by individual $x$, individual $y$ should transfer as much of $\mathrm{P}$ in $w_{2}$ as is compatible with $y$ 's own knowledge.

I would like to close this section by making a quick comparison between the event that is given by the perfective and the 'extensional element' of Landman's Progressive. In his analysis, the extensional component is a stage of an event in the actual world. With the perfective, the extensional component is an entire event whose properties are not directly specified in the actual world but rather in some accessible world.

It is crucial for the event in its entirety to happen in the actual world (this presumably comes from the temporal restriction, which places the running time of the entire event within the 
reference time). When we look at complex events, such as achievements, the actuality entailment includes the culminating point, not just the process. Consider the following example:

(57) Lizzie a pu peindre un tableau.

Lizzie could-pfv paint a picture

(57) is false if Lizzie painted parts of a picture but didn’t finish it. To ensure that the whole event happens in the actual world, the existential quantification has to be done over the largest event in its entirety. The precise decomposition of achievements is a matter of lexical semantics (e.g., is there a complex event, or a pair of events?). For our purposes, whatever mechanism is responsible for understanding an achievement as having culminated with perfective aspect, as in 'Lizzie a peint un tableau' (Lizzie has painted a picture) will handle our modalized case in (57).

\section{4. INTERACTION WITH NEGATION}

I have proposed that aspect moves above the modal, and below tense. How does it interact with negation? We might expect a scope ambiguity between the existential quantifier over events and negation. However, it seems that we only get one interpretation. Consider the following examples:

(58) Darcy n’a pas pu s'enfuir.

Darcy NE has can-pfv escape.

'Darcy wasn't able to escape'

It seems that negation is interpreted above aspect, as in (a). The meaning in (b) is unattested (in fact I am not sure what it would mean):

(59) a. There was no event s.t. in some accessible world it is an escaping event by Darcy $\Rightarrow$ There was no escaping in the actual world, nor in any accessible worlds.

b. There was an event e s.t. in no accessible world e is an escaping event by Darcy.

Why should that be? Negation is supposed to be high (somewhere between $\mathrm{T}$ and $\mathrm{A}$ ), and the fact that aspect cannot pass T might suffice to rule (b) out. But this might be contingent on our theory of Tense (and negation). Another possibility to rule (b) out is that it might be uninformative beyond salvation: all (b) says is some event occurred, and in no accessible world was it an escape: there are more parsimonious and less misleading ways to say 'something 
happened'. Note that it is possible to have a low negation overtly, as in 'Darcy a pu ne pas s'enfuir' (Darcy could not-escape), which roughly means 'Darcy was able to avoid escaping', but this is simply a case of constituent negation.

\subsection{Is the Modality Detectable?}

Recall from the introduction that there was a question of whether the modality completely disappears in the presence of perfective morphology. We now see that the modal is still there, and that the actuality entailment arises because the event is bound in the actual world. One question that comes up is whether the presence of the modal goes undetected or not. In order to see that the modality is still present, and truth-conditionally detectable, we need to turn specifically to goal-oriented interpretations.

\subsubsection{The Case of Goal-Oriented Modals}

Goal-oriented modals differ from ability modals in (at least) three respects: first of all, they involve a purpose clause (the goal). Secondly, while both types of modals involve circumstantially accessible worlds, the meaning of an ability, as is commonly understood, primarily involves physical and mental capacities, while a goal-oriented interpretation might be more sensitive to surrounding factors, rather than intrinsic factors. Finally, while there is a clear dual to goal-oriented possibility (can), namely goal-oriented necessity (must), there is arguably no such dual for the ability modal (cf. Hackl 1998, for why there is no dual to ability can). However, there are borderline cases which make it difficult to give a categorical distinction between the two: sometimes, it appears that an ability relies more on extrinsic properties (e.g., Darcy can see Lizzie from where he stands). Moreover, one can always imagine an implicit purpose clause with every ability modal construction, some sort of justification for one's actions: one doesn't just randomly lift tables: maybe one is trying to impress someone else, or trying to test one's abilities, etc... What links these two modals, as well as purely circumstantial modality (involved in examples such as 'hydrangeas can grow here') is precisely that they involve circumstantial modality. This type of modality is used 'when we are interested in the necessities implied and possibilities opened up by certain facts'. 'Circumstantial modality is the modality of rational agents like gardeners, architects or engineers' (Kratzer 1991), it has explanatory power. In uttering a sentence such as 'I had to sneeze' one does more than simply state a fact (the fact that I sneezed). What the modality contributes is a sort of explanation (Kai von Fintel, pc): the 
circumstances at that time (it is the beginning of allergy season, I am outdoors, pollen is flying around my nose, etc...) explain the inevitability of my sneezing: in all of those worlds in which these circumstances hold, I sneeze.

Where does the explicit purpose clause fit in? Following von Fintel and Iatridou $(2004 a)^{12}$, I take the purpose clause to be an argument of the modal, which further restricts the modal base. Note in passing that, so far, I have ignored the ordering source, which plays an important role in the data von Fintel and Iatridou want to account for. For our purposes, it is still fine to ignore it at this point: if an event happens in some best accessible world, rather than some (plain) accessible world, and is an event with a set of essential properties $\mathrm{P}$ in that world, then, in the actual world where it also happens, it will have the same set of properties.

(60) a. Jane a pu prendre le train pour aller à Paris.

b. $\exists \mathrm{e}\left[\mathrm{e}\right.$ in $\mathrm{w}^{*} \& \tau(\mathrm{e}) \subseteq \mathrm{t}\left\{\mathrm{t}<\mathrm{t}^{*}\right\} \& \exists \mathrm{w}^{\prime} \in \operatorname{Acc}\left(\mathrm{w}^{*}\right) \&$ J-go-to-P. in $\mathrm{w}^{\prime}$ : take-train( $\left.\left.\mathrm{w}^{\prime}, \mathrm{e}, \mathrm{J}\right)\right]$

c. 'There is an event in the actual world contained within an interval in the past, and there is a circumstantially accessible world where Jane goes to Paris in which that event is a taking the train event by Jane'

(61) a. Jane a dû prendre le train pour aller à Paris.

b. $\exists \mathrm{e}\left[\mathrm{e}\right.$ in $\mathrm{w}^{*} \& \tau(\mathrm{e}) \subseteq \mathrm{t}\left\{\mathrm{t}<\mathrm{t}^{*}\right\} \& \forall \mathrm{w}^{\prime} \in \operatorname{Acc}\left(\mathrm{w}^{*}\right) \&$ J-go-to-P. in $\mathrm{w}^{\prime}$ : take-train( $\left.\left.\mathrm{w}^{\prime}, \mathrm{e}, \mathrm{J}\right)\right]$

c. 'There is an event in the actual world contained within an interval in the past, and in all circumstantially accessible worlds where Jane goes to Paris, that event is a taking the train event by Jane'

One question that may come to mind is whether, when we get an actuality entailment, the goal also has to hold in the actual world. Data suggest that it may not need to ${ }^{13}$ :

(62) Jane a pu prendre l'avion pour aller à Londres, mais l'avion a été détourné vers Manchester, et elle n'est jamais arrivée à Londres.

Jane could-pfv take the plane to go to London, but the plane got rerouted to Manchester, and she never reached London.

\footnotetext{
${ }^{12}$ von Fintel and Iatridou (2004a) are primarily concerned with goal-oriented modal statements of the form 'If you want to go to Paris, you have to take the train', which comes with its set of complications having to do with the composition of the if-clause and want, that I won't cover here. What matters for our purposes is that they assume that goal-oriented constructions of both types have a purpose clause (explicit or implicit) as an argument of the modal, which I do here as well.

${ }^{13}$ Speakers may differ on whether the goal has to obtain in the actual world. My French informants all agree with the judgment in (62). Italian speakers split into two groups. I won't explore what underlies this split in acceptance, and simply suggest that it may have to due with the way the purpose clause is interpreted. Note that when it is fronted, the judgment gets degraded, but still acceptable for speakers that accept (62).
} 
In (62), it is definitely entailed that Jane took the plane. Any continuation that would deny this would be a contradiction. However, the continuation here suggests that the goal doesn't have to be reached in the actual world. This is actually what the account predicts. From the cross-world event identification principle we get that in the actual world the event is a taking the plane event. However, while in some world this event holds and Jane also goes to Paris, the purpose clause restricts only the modal: it doesn't have to hold in the actual world. ${ }^{14}$

Going back to the truth conditional contribution of the modals, we see that (60) and (61) happen to differ truth conditionally in a scenario where Jane had other options for going to London (e.g., taking the plane, riding a horse, etc.). In this scenario, (60) is true, and (61) false. The reason why the latter is false is that in all circumstantially accessible worlds where Jane goes to London, she takes the train. There is thus no accessible world in which she reaches her goal but doesn’t take the train, i.e., there is no possibility to ride a horse or take a plane...

\subsubsection{Root Modals and Implicatures}

We thus see that we get a truth conditional difference between a universal and an existential modal, even with an actuality entailment. While both require that the event in the complement take place in the actual world, as for the unmodalized version in (a) below, the necessity modal further requires that it takes place in all accessible worlds. In other words, Jane has no choice.

(63) a. Jane a pris le train pour aller à Paris. Jane took-pfv the train to go to Paris

b. Jane a pu prendre le train pour aller à Paris. Jane could-pfv take the train to go to Paris

c. Jane a dû prendre le train pour aller à Paris. Jane had to-pfv take the train to go to Paris

There is one additional meaning component involved in (b), namely the intuition that the train was Jane’s preferred mean of transportation. No such inference arises with (a) nor (c).

\footnotetext{
${ }^{14}$ Nissenbaum (2005) offers a slightly different analysis than von Fintel and Iatridou, where the purpose clause is merged directly with the complement, that is, (61) should be parsed as 'Jane had to [take the train to go to Paris]':

a. $\exists \mathrm{e}\left[\mathrm{e} o \mathrm{w}^{*} \& \tau(\mathrm{e}) \subseteq \mathrm{t}\left\{\mathrm{t}<\mathrm{t}^{*}\right\} \& \forall \mathrm{w}^{\prime} \in \operatorname{Acc}(\mathrm{w})\right.$ : [take-train (w’,e) \& $\forall \mathrm{w}^{\prime \prime}$ compatible with the goal of e, J. goes to Paris in $\left.\mathrm{w}^{\prime \prime}\right]$

b. 'There is an event in $\mathrm{w}^{*}$ contained within an interval in the past, and in all circumstantially accessible worlds, that event is a taking the train by Jane with the goal of going to Paris'
}

Here as well and because the purpose clause is modalized, the goal also doesn't have to hold in w*, simply because the event described by the complement obtains. Thus, as far as our data is concerned, either account will do. 
Another impression informants report for (b) is that Jane didn't expect to be able to take the train at first, but when that option became open she jumped on it, again matching the intuition that taking the train was a desirable outcome. Similar intuitions accompany the ability modal:

Jane a pu soulever cette table.

In (64) we get the impression that Jane's being able to lift the table was somewhat unexpected (she just recovered from a broken arm, or the table is particularly heavy). Bhatt (1999) captures this intuition for the ability modal by stating that ABLE comes with a conventional implicature that some effort is involved with the realization of the complement.

In the present account, how can we cash out these intuitions? Where does this desirability inference come from? It seems to be an implicature, which can be cancelled:

(65) She was able to take the train. In fact she would have preferred to fly, but there was no other way to go to Paris.

The implicature would arise as follows: can and must are scalar alternatives, with must being the stronger of the two, given that must $p$ entails can $p$. Upon hearing (63)b), one will infer that the speaker is not in a position to assert ((63)c). Thus, he will infer that there are accessible worlds in which Jane goes to Paris but where the event of taking the train doesn't happen, further implying that there are other ways for Jane to reach her goal of going to Paris (i.e., there are other accessible worlds where Jane goes to Paris which do not have a taking the train event). He will then deduce that Jane had options. Because she took the train, while having options, taking the train must have been preferable. The unmodalized (a) doesn't have a competitor, hence no such inference arises. Similarly for the ability modal, because the modal is existential, we infer that there are accessible worlds, where Jane has the abilities that she has and the circumstances are the same, where there is no event of lifting the table, which implies that the event described by the complement is not a trivial outcome.

\section{DERIVING NON IMPLICATIVE READINGS}

Recall from the introduction that actuality entailments only arose with perfective aspect. Assuming that perfective and imperfective differ only in the direction of the inclusion relation between the running time of the event and the reference time, we expect that imperfective should also yield actuality entailments. However, we have reasons to believe that the semantics of the 
imperfective cannot be that simple. For one, imperfective morphology covers a wide range of cases: progressive (a), generics (b), counterfactuals (c), etc., all of which seem to involve some modal dimension (cf. Bonomi 1995, Cipria and Roberts 2000, Ferreira 2005, among many others). For progressive, we seem to need to invoke worlds in which the event goes uninterrupted; for generics, we need to invoke 'normal' or 'ideal' events; with counterfactuals, we need worlds where the antecedent holds:

(66) a. Jane traversait la rue, quand elle s'est fait écraser. Jane cross-pst-impf the street, when she got crushed. 'Jane was crossing the street, when she got hit by a car'

b. A l'époque, les femmes portaient des corsets. Back in the days, women wore-impf corsets

c. S'il était arrivé hier soir, il voyait Jane. [adapted from Ippolito 2004] If he had arrived last night, he saw-impf Jane 'Had he arrived last night, he would have seen Jane.'

While all of the above constructions involve some modal element, it isn't obvious that a unified semantics of the imperfective, which can handle all of these uses (but see Cipria and Roberts 2000). Following Hacquard (2006), I assume that there is no semantic object 'imperfective'. Instead, I treat imperfective morphology as a default spell-out of past tense, in all environments where perfective morphology isn't licensed. What is responsible for the various readings of the imperfective are various aspectual operators: a generic, a counterfactual, and a progressive operator, which all trigger imperfective morphology (cf. also Iatridou 1990; Giorgi and Pianesi 2004).

For reasons of space, I cannot give a full account of the imperfective and its role in deriving non implicative readings with root modals. My claim in this section is rather simple: lack of implicative readings (no actuality entailment) indicates presence of an additional modal element. Consider the following example, where a root modal with perfective is overtly embedded under another modal element (here the attitude predicate think):
a. Darcy pense que Jane a pu
s'enfuir.
Darcy thinks that Jane can-PAST-pfv escape
'Darcy thinks that Jane was able to escape'

b. $\forall w^{\prime}$ compatible with D's beliefs in $w^{*}$ : $\exists$ e: e in w' \& $\exists$ w' ' $\in \operatorname{Circ}\left(w^{\prime}\right)$ : escape(e,J,w') 'In all worlds w' compatible with Darcy's beliefs in $w^{*}$, there is an event which in some world w' compatible with Jane's abilities in w' is an escaping event.' 
The above sentence doesn't make any claim about whether Jane escaped or not in the actual world, but, rather, makes a claim about an escaping event by Jane in Darcy’s belief worlds. We see that, even when aspect moves above the existential modal, aspect's world argument is still not bound by the matrix binder, but rather by the world binder provided by the attitude: hence no claim is made about an actual event. This kind of examples suggests that the presence of an extra modal element removes actuality entailments with root modals. Thus, given that aspectual operators associated with imperfective morphology have a modal component independently, I hypothesize that this modal element is responsible for the lack of actuality entailments in root modals with imperfective.

There are two main types of 'non implicative' readings associated with root modals: a general ability (as in (a)), reminiscent of generic statements, and a counterfactual one (as in (b)):

a. Elisabeth pouvait parler aux singes.

Elisabeth could-impf talk to monkeys.

b. Jane pouvait prendre le train, (si elle voulait).

Jane could-impf take the train, (if she wanted to).

What (a) means, intuitively is that Elisabeth has a relatively long-lasting ability, namely that of talking to monkeys, which she may or may not have ever exercised. (b) on the other hand, seems to be bound to a particular situation, where Jane could have taken the train, and most likely, did not in fact take it. In the remainder of this section, I show how to derive these readings, using a generic and a counterfactual operator.

\subsection{DeRiVing the Ability MeAning}

This section focused on the ability reading of imperfective on root modals, illustrated below:

a. Elisabeth pouvait parler aux singes.

Elisabeth could-impf talk to monkeys.

b. Cette voiture pouvait faire du $250 \mathrm{~km} / \mathrm{h}$.

This car could-impf go $250 \mathrm{mph}$.

Given the non accidental nature of the ability attributed to Elisabeth, and given Bhatt's (1999) evidence for these readings being associated with genericity (notably with the interpretation of bare plurals in English), I assume that this reading is to be derived through a generic operator. A 
generic operator is an unselective binder over individuals or events, used to describe generalizations which tolerate exceptions, and in fact, don't even require verifying instances. Consider the following sentences, which have been argued to involve genericity. ((70)b) is an example of a kind-referring generic, which here involves a bare NP, (70)a) is a case of a characterizing sentence generic (cf. Krifka et al., 1995)):

(70) a. This machine crushes oranges.

b. Navy officers dress handsomely.

As Krifka et al. argue, the example in (70)a) doesn't require verifying instances: it will still be judged true if the machine has never been used before. I use the following semantics for GEN from Hacquard (2006), adapted from von Fintel (1997). GEN is a quantifier over events (or individuals) and is restricted by a selection function which picks out only normal or ideal events (from the perspective of $\mathrm{w}$ at $\mathrm{t}$ ), and says that for all those ideal events which obey certain preconditions (given by p), q holds:

(71) For $\sigma$ either e or $\varepsilon$, for all $p, q \in D_{<\sigma, t>}, f \in D_{<s<\sigma, t>}$ :

$\llbracket \operatorname{GEN} \rrbracket(f)(p)(q)$ is true in $w$ at $t$ iff $\forall x \in f(w, t): p(x) \rightarrow q(x)$ where $f(w, t)=\lambda x$. $x$ is normal/ideal from the perspective of $w$ at $t$.

We thus obtain the following:

(72) a. Elisabeth can talk to monkeys

b. $\forall \mathrm{e}$ [e is normal from the perspective of $\mathrm{w}^{*}$ at $\mathrm{t}^{*}$ : if e's preconditions hold $\rightarrow \exists \mathrm{w}^{\prime} \in \mathrm{CIRC}\left(\mathrm{w}^{*}\right)$ talk-to-monkeys (e,w') \& Ag(e,E.)

'For all normal/ideal events from the perspective of $w$ at $t$, where preconditions for talking to monkeys are met, there is a world w' circumstantially accessible from $w^{*}$ where $e$ is a talking to monkeys event by E.'

The lack of actuality entailment comes from the selection function of GEN, which picks out normal/ideal events that may not be instantiated in the actual world. In the zoo context, for instance, the preconditions may not be met: Elizabeth must not have been talking to monkeys.

This analysis can make sense of the fact that the following pair of sentences has a very similar meaning: 
a. This car drives 200mph.

$\forall \mathrm{e}\left[\mathrm{e}\right.$ is normal from the perspective of $\mathrm{w}^{*}$ at $\mathrm{t}^{*}$ : if e's preconditions hold

$\rightarrow$ drive-200mph(e, this car)

'All normal events e where preconditions are met, e.g., good road conditions, car is not broken, no speed limit enforcer, etc... are events of driving the car 200mph.'

b. This car can drive 200mph.

$\forall \mathrm{e}\left[\mathrm{e}\right.$ is normal from the perspective of $\mathrm{w}^{*}$ at $\mathrm{t}^{*}$ : if e's preconditions hold $\rightarrow \exists \mathrm{w}^{\prime} \in \operatorname{CIRC}\left(\mathrm{w}^{*}\right)$ drive-200mph(e, w, this car)

'All normal events e where preconditions are met, e.g., good road conditions, car is not broken, no speed limit enforcer, etc... there is a world compatible with circumstances s.t. $e$ is a driving the car 200mph.'

What underlies this similarity is the same reasoning that applied to pairs of sentences involving a root can with perfective morphology, and its unmodalized equivalent, as illustrated below. Both sentences are true just in case Jane danced. Recall that in a sentence like (74)a), we have an actual event which in some circumstantially accessible world is a dancing event. We infer that it is a dancing event in the actual world as well, given that it is the same event:
a. Jane a pu danser. Jane can-pst-perf dance
b. Jane a dansé. Jane dance-pst-perf

The same reasoning applies to (73)b): all normal events e from the perspective of the actual world (and where some preconditions hold) are such that in some circumstantially accessible world they are driving 200mph events. Given the event identification principle, all normal events (where some preconditions hold) will basically be driving 200mph events.

\subsection{Deriving the Counterfactual Meaning}

To derive the counterfactual reading, I assume that a sentence like (75)a) below is equivalent to the one in (b): I assume that in (a) imperfective reflects the presence of a (primitive) counterfactual modal, which can also be expressed by an overt future + imperfective (i.e., conditionnel morphology) as in (b). I take this counterfactual modal to universally quantify over metaphysical worlds (in the sense of Condorvadi 2001, i.e., ways the world might turn out to be) and introduce an open time interval whose starting point is the time provided by tense (for arguments for treating this counterfactual modal as a primitive, see Hacquard 2006, and 
references therein). I think that, in these cases, we assume a default implicit antecedent clause (probably brought out by the goal-orientation of the modal), which means something like if she had wanted to, or if she so desired. Note that the counterfactual modal is right below tense (it needs a time argument for to set the left boundary of the open interval it introduces), and above a perfective aspect, which quantifies over the event in the complement:

a. Jane pouvait prendre le train, (si elle voulait). Jane could-impf take the train, (if she wanted to).

b. Jane aurait pu prendre le train, (si elle avait voulu). Jane could have taken the train, (if she had wanted to).

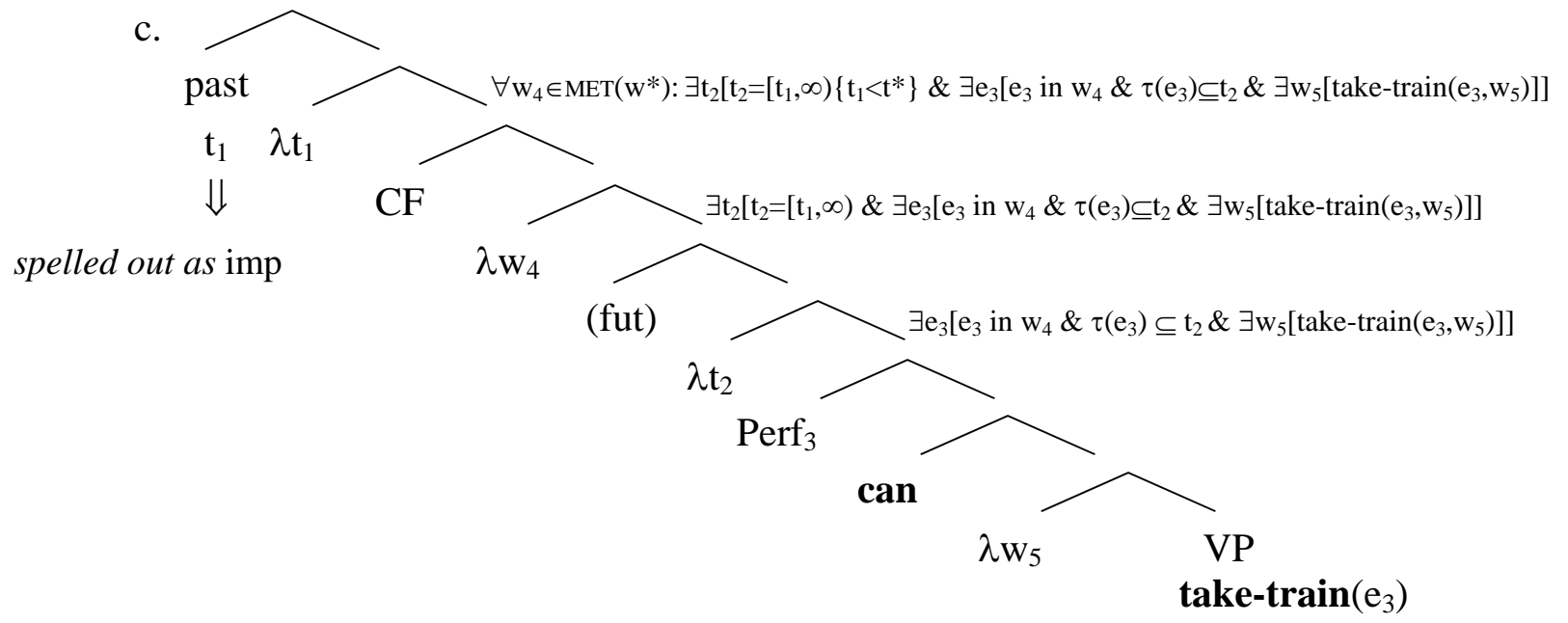

d. 'There is a salient past time $t_{1}$ s.t in all metaphysical worlds, there is an open time interval $t_{2}$ whose left boundary is $t_{1}$ such that there is an event $e_{3}$, whose running time is included within the interval $t_{2}$, which in some circumstantially accessible world is a taking the train event.'

What both (a) and (b) mean is that at some past time, if Jane had wanted to, it would have been possible for her to take the train: in all metaphysically accessible worlds, there is a world where she takes the train (there is a completed event of her taking the train in that world in a time interval starting from that past time on). This doesn't preclude that there might have been other means to reach her goal, in other metaphysically accessible worlds. We can thus continue the sentence with 'she could also have taken the plane'. Note in passing that the metaphysical accessibility relation naturally captures the future-orientation of root modals we get with imperfective.

I have glossed over many details involved in the (non implicative readings associated with) imperfective. My main point is that we independently need imperfective to express 
counterfactuality and genericity, and that these operators are responsible for the lack of actuality entailments with imperfective morphology on root modals: they do not force the event to take place in the actual world.

\section{Previous Proposals}

In this section, I would like to compare my proposal to previous ones. The two proposals I am aware of come from Bhatt (1999) and Piñón (2003), which both deal with the ability modal ${ }^{15}$.

\section{1. ВНАTT (1999)}

Bhatt (1999) was the first to discover that the ability modal is implicative with perfective, and non implicative with imperfective, in languages that have an overt morphological distinction ${ }^{16}$. In his analysis, the ability modal is at base implicative: it has the semantics of an implicative predicate like manage, meaning that what is being asserted is the complement clause itself (following Kartunnen's (1971) analysis of implicatives). In order to derive the full meaning of this construction, Bhatt proposes a conventional implicature, parallel to that of manage (cf. Karttunen and Peters 1979), which states that some effort went into the realization of the complement clause. This yields the implicative reading associated with perfective morphology.

(76) Jane a pu soulever la table.

Jane could-pfv lift this table

ABLE(lift-this-table)(Jane)

Assertion: Jane lifted this table

Implicature: Some effort was involved in lifting this table

For the modal reading Bhatt takes the imperfective morphology to reflect the presence of a generic operator (GEN), based on morphological evidence in Hindi, and generic readings of bare plurals in English. When GEN is present (imperfective), the complement clause doesn't need to be actualized (GEN doesn't require verifying instances). His analysis is represented below:

Jane pouvait soulever la table.

Jane could-pfv lift this table

GEN(ABLE(lift-this-table))(Jane)

\footnotetext{
${ }^{15}$ It has recently been brought to my attention that Borgonovo and Cummins are currently working on this issue. I will wait until the completion of their paper, to evaluate their proposal.

${ }^{16}$ Thalberg (1972) was the first to note an ambiguity between an 'ability' and an implicative reading, see also Karttunen (1971); however, neither of them linked the difference in behavior to aspect.
} 
Because GEN doesn't require verifying instances, in (77), Jane doesn't need to have lifted the table for the sentence to be true (as long, presumably, as there are-non-actual—situations or worlds that satisfy the restriction of the genericity operator, in which she does lift the table).

One setback in Bhatt's proposal is that his treatment of the ability modal doesn't allow any connection with other interpretations of the same modal. There is no way to relate his analysis of ABLE to epistemic and deontic possibility, which, for instance in French, is expressed using the same lexical word, i.e., pouvoir. If we followed Bhatt's account, we would essentially have to treat epistemic pouvoir and ability pouvoir as two homonyms. More suspicious is the fact that this lexical ambiguity is to be found in language after language: the same lexical item is used for deontic, epistemic or circumstantial possibility ${ }^{17}$. One may argue, however, that more and more analyses of different modal constructions give each of them a unique treatment (cf. MacFarlane, 2003 for epistemics; Ninan 2005 for deontics, etc...), and it may turn out that the homonymy problem is more of a polysemy problem: two modals would still perform similar functions and while they may be listed as distinct entries in the lexicon, they could share a common etymology. Interestingly, a similar controversy arises with analyses of the imperfective, which, cross-linguistically, covers different meanings (progressivity, habituality, counterfactuality...). While some authors try to give a common meaning to a couple of uses (cf. Ferreira 2004, Cipria and Roberts 1997), most give independent accounts for each interpretation. Still, a major advantage of Kratzer's account of modals is that it derives their meaning difference through contextual factors (the conversational backgrounds), which intuitively makes a lot of sense. One would prefer a unified account, if available, to one that takes as completely accidental the fact that, cross-linguistically, the same lexical items have the same range of meanings.

Furthermore, given that goal-oriented modals follow the same pattern, we need an account that will apply to the two modal senses in any case. And even if we could extend this proposal to the goal-oriented cases, by treating both the possibility and the necessity modals as underlyingly implicative predicates, it is not clear how we could then possibly derive truthconditional differences between the possibility and the necessity modals, as the ones we saw in section 2.4. (Both would be implicative predicates, and whatever meaning differences would have to be on the implicature/presuppositional level.)

\footnotetext{
${ }^{17}$ Thanks to Sabine Iatridou, p.c. for insisting on this point.
} 
The present account avoids these problems: it allows the ability modal to have an implicative meaning with perfective, while keeping a connection with the other senses of a possibility modal: it is still an existential quantifier over possible worlds. The crucial difference between the ability modal and the epistemic possibility modal is structural: one scopes below and the other above aspect. However in both of its senses, the possibility modal (pouvoir) refers to some possible world among a set of accessible worlds, this set being determined by context. Thus we maintain the benefits of a Kratzerian account, while accounting for Bhatt's data.

Another problem with Bhatt's account, which he points out himself, is that we may expect that when real implicatives (like manage)—which share the same semantics as Bhatt's ABLE - combine with imperfective morphology, they should lose their implicative behavior (no actuality entailment). But, as the following example shows, this is not so:

(78) Darcy réussissait à soulever cette table, \#mais il ne la soulevait pas. Darcy succeed-imp to lift this table, \#but he didn’t lift-impf it.

Bhatt's suggestion is that there are two sorts of genericity operators, a 'universal' and a 'dispositional' one, and only the latter does not require verifying instances. However this is a reformulation of the problem: why it is that real implicatives can only combine with a universal genericity operator?

Again, the present account is shielded from this sort of criticism, since my semantics for the modal is not that of an implicative predicate: the implicative reading arises from a combination of factors: a mechanical one (existential closure occurs above the scope of the modal) and a condition on event identity.

\subsection{PIÑÓN (2003)}

Piñón (2003) offers an interesting proposal for the two uses of English able which he identifies as an 'opportunity-able' and an 'ability-able', and which correspond to the implicative and non implicative uses of the ability modal. He proposes to derive the implicative readings of English able through scopal differences between a possibility modal and a past tense. Piñón suggests that for opportunity-able, we are dealing with a historical possibility, where the modality is trivialized as it scopes above a past tense (if it is historically possible that past $\mathrm{p}$, then it has to be the case that past p). For reasons of space, I won't give a full account of the proposal and refer the 
interested reader to Piñón (2003). I will simply point out a few challenges that his proposal faces if we try to extend it to our modal auxiliaries. First, Piñón doesn’t relate the implicative behavior with aspect, so it is not clear why perfective would always yield actuality entailments, but not imperfective aspect. Second, it is not clear either how to extend this proposal to the goal-oriented cases (although the modality there could also be argued to be historical possibility/necessity). Third, the strength of the proposal is that it derives the implicative reading solely from a difference in scope. There is a wrinkle to this proposal however, in that the two readings do not strictly differ in terms of scope: implicative/opportunity able takes Tense as an argument, while ability able doesn't ${ }^{18}$ :
a. $\quad$ able_a $=\lambda \mathrm{R} \lambda \mathrm{x} \lambda<\mathrm{t}, \mathrm{h}>[\vartheta(<\mathrm{t}, \mathrm{h}>$, agent $(\mathrm{x}, \mathrm{R}))]$
b. able_o $=\lambda \mathrm{T} \lambda \mathrm{R} \lambda \mathrm{x} \lambda<\mathrm{t}, \mathrm{h}>[\diamond(<\mathrm{t}, \mathrm{h}>$, T agent $(\mathrm{x}, \mathrm{R}))]$

\section{CONCLUSION}

This paper was an attempt at deriving actuality entailments when perfective appears on root modals without having to give up a standardized semantics for aspect, nor modal auxiliaries. I have proposed that the entailment comes about when aspect moves above a modal ${ }^{19}$, as aspect comes with its own world variable. This world variable, being outside the scope of the modal, has to be bound by the matrix world binder, thereby yielding an actual event. We then infer that that event has the same properties in the actual world as it does in the accessible worlds in which it also occurs. This happens via some default identification principle, at work when looking at events across worlds. I further showed that the lack of implicative readings available with imperfective could be due to the imperfective itself reflecting an additional layer of modality (either counterfactuality or genericity). One question that I haven’t fully addressed here, is why it

\footnotetext{
${ }^{18}$ Thanks to K. von Fintel for pointing this issue out.

${ }^{19}$ I have proposed that aspect is base-generated as an argument of the verb and moves up for type-reasons. The primary motivation for choosing this non standard view of aspect, was to push the parallel between events and individuals on the one hand, and maintain a single lexical entry for modals. Thinking in terms of movement give us an interesting avenue to explore when we contrast the possible combinations of various aspects and modal interpretations (see Hacquard 2006). Note, however, that my proposal would be compatible with a more standard view of aspect, where aspect would be base-generated under Tense. If this were the case, we would need to assume that modals come with two different types. Epistemics, which scope above tense and aspect would take propositions as their complements, while roots, which scope under aspect, would take predicate of events. To make the proposal more uniform, we could say that modals have a Boolean semantics, they are of type $\langle\alpha, \alpha>$, (where $\alpha$ is either $<$ st $>$ or $<\varepsilon$,st $>$ ), that is they either take propositions and return propositions, or they take predicates of events and return predicates of events. I leave a detailed comparison between the two possibilities for future research.
} 
is that epistemics and addressee-oriented deontics are immune to the effect. We saw in section 1.2. that they are interpreted above tense and aspect, and hence I assumed that they were merged in this high position. Thus, given the picture presented here, when aspect moves out of the VP (quantifier movement) to $\mathrm{T}$, this movement still occurs under the modal: hence aspect's world variable gets bound by the modal (the closest world binder), forcing the event to occur in the worlds quantified over by the modal, but not necessarily in the actual world: we thus expect no actuality entailment.

\section{REFERENCES}

Abusch, D.: 1997, 'Sequence of Tense and Temporal de re'. Linguistics and Philosophy 20-1. Anderson, A. R.: 1951, 'A note of Subjunctive and Counterfactual Conditionals'. Analysis 12.

Bonomi, A.: 1997, 'Aspect, Quantification and when-clauses in Italian'. Linguistics and Philosophy 20, 469-514.

Bhatt, R.: 1998, 'Obligation and Possession', in H. Harley (ed.) Papers from the UPenn/MIT Roundtable on Argument Structure and Aspect, MITWPL 32. Cambridge, MA: MITWPL.

Bhatt, R.: 1999, Covert Modality in Non-Finite Contexts. Ph.D. Thesis, Penn

Brennan, V.: 1993, Root and Epistemic modal auxiliary verbs, Ph.D. Thesis, University of Massachusetts, Amherst.

Brogonovo, C. and S. Cummins: 2006, 'Past-Tense Modals in Spanish and French', paper presented at the 16e Coloquio de Gramática Generativa, Madrid, handout.

Butler, J.: 2003, ‘A Minimalist Treatment of Modality’. Lingua 113, 967-996.

Carlson, G., N.: 1977, Reference to Kinds in English. Ph.D. Thesis, UMass, Amherst.

Chierchia, G.: 1995, 'Individual-level predicates as Inherent Generics', in G. N. Carlson \& F. J. Pelletier (eds.) The Generic Book, Chicago: The University of Chicago Press.

Chisholm, R. M.: 2002, 'Identity through Time', in Kim and Sosa (eds.) Metaphysics, An Anthology. Blackwell.

Cinque, G.: 1999, Adverbs and Functional Heads: A Cross-Linguistic Perspective, Oxford Studies in Comparative Syntax. Oxford and New York: Oxford University Press.

Cipria, A. and C. Roberts: 2000, 'Spanish Imperfecto and Preterito: Truth Conditions and Aktionsart Effects in Situation Semantics’. Natural Language Semantics 8.

Condoravdi, C.: 2001, 'Temporal Interpretations of modals', in D. Beaver, S. Kaufman, B. Clark (eds.) Stanford Papers in Semantics. Palo Alto: CSLI Publications.

Dahl, O.: 1975, 'On Generics', in E. Keenan (ed.) Formal Semantics of Natural Language. Cambridge: Cambridge University Press.

Davidson, D.: 1967, 'The Logical Form of Action Sentences', in N. Rescher (ed.) The Logic of Decision and Action. Pittsburg: University of Pittsburg Press, 81-120.

Dowty, D.: 1977, “Towards a semantic analysis of verb aspect and the English 'imperfective' progressive”. Linguistics and Philosophy, 1, 45-77.

Dowty, D.: 1979, Word Meaning and Montague Gramar. Dortrecht: Reidel.

Drubig, H. B.: 2001, 'On the syntactic form of epistemic modality', ms. Available at http://www.sfb441.uni-tuebingende/b2.papers/DrubigModality.pdf.

Ferreira, M.: 2005, Event Quantification and Plurality. Ph.D. Thesis, MIT.

Feldman, F.: 1986, Doing the Best We Can. Dortrecht: Reidel. 
von Fintel, K.: 1997. 'Bare Plurals, Bare Conditionals, and Only’. Journal of Semantics 14, 1-56.

von Fintel, K.: 1999. 'NPI-Licensing, Strawson-Entailment, and Context-Dependency’. Journal of Semantics 16.1.

von Fintel, K.: 2001, Advanced Semantics Seminar, lecture notes, MIT.

von Fintel, K. and S. Iatridou: 2004a, 'What to do if you want to go to Harlem: Notes on Anankastic Conditionals and Related Matters', ms., Massachusetts Institute of Technology, available at: http://web.mit.edu/fintel/www/harlem.pdf

von Fintel, K. and S. Iatridou: 2004b, Seminar on Modality, lecture notes, Massachusetts Institute of Technology.

von Fintel, K. and S. Iatridou: 2005, 'Anatomy of a Modal', in J. Gajewski, V. Hacquard, B. Nickel and S. Yalcin (eds.) New Work on Modality, MITWPL 51. Cambridge, MA: MITWPL.

Giorgi, F. and A. Pianesi: 1997, Tense and Aspect. From Semantics to Morphosyntax. Oxford: Oxford University Press.

Giorgi, F. and A. Pianesi: 2004, 'On the Speaker's and the Subject's Temporal Representation' in J. Guéron and J. Lecarme (eds.) The Syntax of Time. Cambridge, MA: MIT Press.

Hackl, M.: 1998, 'On the Semantics of “Ability Ascriptions', ms., Massachusetts Institute of Technology.

Hacquard, V.: 2006, Aspects of Modality. Ph.D. Thesis, MIT.

Heim, I.: 1992, 'Presuppositions Projection and the Semantics of Attitude Verbs'. Journal of Semantics 9, 183-221.

Hintikka, J.: 1962, Knowledge and Belief. Cornell University Press.

Hintikka, J.: 1969, 'Semantics for Propositional Attitudes' in J. W. Davis et al. (eds.) Philosophical Logic. Dortrecht, 21-45.

Iatridou, S.: 1990, 'The Past, the Possible and the Evident', Linguistic Inquiry 21.1, 123-129.

Iatridou, S.: 2000, 'The Grammatical Ingredients of Counterfactuality’. Linguistic Inquiry 31.2.

Ippolito, M.: 2004, 'Imperfect Modality’, in J. Guéron and J. Lecarme (eds.) The Syntax of Time. Cambridge, MA: MIT Press.

Jackendoff, R.: 1972, Semantic Interpretation in Generative Grammar. Cambridge, MA: The MIT Press.

Karttunen, L.: 1971, 'Implicative Verbs’. Language 47, 340-358.

Kayne, R.: 1991, 'Romance Clitics, Verb Movement, and PRO’. Linguistics Inquiry 22-4.

Klein, W.: 1994, Time in Language. London/New York: Routledge.

Kratzer, A.: 1977, 'What must and can must and can mean'. Linguistics and Philosophy 1.

Kratzer, A.: 1981, 'The notional category of modality' in H.-J. Eikmeyer and H. Rieser (eds.), Words, Worlds, and Contexts. New Approaches in Word Semantics. Berlin: de Gruyter.

Kratzer, A.: 1991, 'Modality', in A. von Stechow and D. Wunderlich (eds.) Semantik: Ein internationales Handbuch zeitgenoessischer Forschung. Berlin: De Gruyter, 639-650.

Kratzer, A: 1996, 'Severing the external argument from the verb', in J. Rooryck and L. Zarin (eds.) Phrase Structure and the Lexicon. Dortrecht: Kluwer.

Kratzer, A.: 1998, 'More Structural Analogies Between Pronouns and Tenses', in D. Strolovich and A. Lawson (eds.) Proceedings of SALT VIII. Ithaca, NY: CLC Publications, Cornell University.

Krifka M., F. J. Pelletier, G. N. Carlson, A. ter Meulen, G. Link and G. Chierchia: 1995, 'Introduction', in G. N. Carlson \& F. J. Pelletier (eds.) The Generic Book, Chicago: The University of Chicago Press. 
Kripke, S.: 1972, 'Naming and Necessity', in D. Davidson and H. Gilbert (eds.) Semantics of Natural Language, Dordrecht: Reidel.

Kusumoto, K.: 2002, 'On the Quantification over Times in Natural Language'. Natural Language Semantics 13, 317-357.

Landman, F.: 1992, 'The Progressive', Natural Language Semantics 1.

Lenci, A. and P. Bertinetto: 2000, 'Aspect, Adverbs and Events: Habituality vs. Perfectivity', in J. Higginbotham, F. Pianesi and A. Varzi (eds.) Speaking of Events. Oxford/New York: Oxford University Press.

Lewis, D.: 1968, On the Plurality of Worlds. Oxford: Basil Blackwell.

Lewis, D.: 1973, Counterfactuals. Cambridge, MA: Harvard University Press.

Lewis, D.: 1975, 'Adverbs of Quantification', in E. Keenan (ed), Formal Semantics of Natural Language. Cambridge, MA: Cambridge University Press, 3-15.

Lewis, D.: 1983, Philosophical Papers. New York/Oxford: Oxford University Press.

Ninan, D.: 2005, ‘Two Puzzles about Deontic Necessity', in J. Gajewski, V. Hacquard, B. Nickel and S. Yalcin (eds.) New Work on Modality, MITWPL 51. Cambridge, MA: MITWPL.

Nissenbaum, J.: 2005, 'Kissing Pedro Martinez: (Existential) Anankastic Conditionals and Rationale Clauses', in Proceedings of SALT XV. Ithaca, NY: CLS Publications, Cornell University.

Palmer, F. R.: 1986, Mood and Modality. Cambridge: Cambridge University Press.

Partee, B.: 1973, 'Some Structural Analogies Between Tenses and Pronouns'. The Journal of Philosophy, 601-609.

Percus, O.: 2000, 'Constraints on some other variables in syntax'. Natural Language Semantics 8, 173-229.

Pianesi, F. and A. Varzi: 2000, 'Events and Event Talk: An Introduction', in J. Higginbotham, F. Pianesi and A. Varzi (eds.) Speaking of Events. Oxford/New York: Oxford University Press.

Piñón, C.: 2003, ‘Being able to’ in G. Garding and M. Tsujimura (eds.) WCCFL 22 Proceedings. Somerville, MA: Cascadilla Press, 384-397.

Portner, P.: 1998, 'The Progressive in Modal Semantics'. Language 74: 760-787.

Portner, P.: 2005, 'The Semantics of Imperatives within a Theory of Clause Types', in K. Watanabe and R. B. Young (eds.) Proceedings of SALT XIV. Ithaca, NY: CLC Publications.

Schubert, L. and F. J. Pelletier: 1989, 'Generically Speaking, or, Using Discourse Representation Theory to Interpret Generics', in G. Chierchia, B. Partee, and R. Turner (eds.) Properties, Types and Meaning II.

Smith, C.: 1991, 'The Parameter of Aspect'. Kluwer Academic Press.

Stalnaker, R.: 1968, 'A Theory of Conditionals'. Studies in Logical Theory. American Philosophical Quarterly.

Stowell, T.: 2004, 'Tense and Modals', in J. Guéron \& J. Lecarme (eds.) The Syntax of Time. Cambridge, MA: MIT Press.

Stone, M.: 1997, 'The Anaphoric Parallel between Modality and Tense'. IRCS Report 97-06, University of Pennsylvania. 